Water vapour above ALOMAR

K. Hallgren et al.

\title{
Climatology of middle atmospheric water vapour above the ALOMAR observatory in northern Norway
}

K. Hallgren ${ }^{1,2}$, P. Hartogh ${ }^{1}$, and C. Jarchow ${ }^{1}$

${ }^{1}$ Max-Planck-Institut für Sonnensystemforschung, Katlenburg-Lindau, Germany

${ }^{2}$ now at: Swedish Defence Research Agency, Stockholm, Sweden

Received: 29 August 2012 - Accepted: 22 November 2012 - Published: 7 December 2012

Correspondence to: K. Hallgren (kristofer.hallgren@foi.se)

Published by Copernicus Publications on behalf of the European Geosciences Union.

Title Page

Abstract

Introduction

Conclusions

References

Tables

Figures

14

4

Back

Full Screen / Esc

Printer-friendly Version

Interactive Discussion 


\section{Abstract}

We have been observing the water vapour line at $22.235 \mathrm{GHz}$ above ALOMAR in northern Norway $\left(69^{\circ} \mathrm{N}, 16^{\circ} \mathrm{E}\right)$ since early 1996 with ground-based microwave spectrometers (WASPAM and cWASPAM) and will here describe a climatology based on these ob-

5 servations. Maintenance, different spectrometers and upgrades of the hardware have slightly changed the instruments. Therefore great care has been taken to make sure the different datasets are compatible with each other. In order to maximise the sensitivity at high altitude for the older instrument a long integration time (168 h) was chosen. The complete dataset was thereafter recompiled into a climatology which describes the 10 yearly variation of water vapour at polar latitudes on a weekly basis. The atmosphere is divided into 16 layers between $40-80 \mathrm{~km}$, each $2.5 \mathrm{~km}$ thick. The dataset, spanning $15 \mathrm{yr}$ from 1996 to 2010, enabled us to investigate the long-term behaviour of water vapour at these latitudes. By comparing the measurements from every year to the climatological mean we were also able to look for indications of trends in the dataset

15 at different altitudes during the time period of our observations. In general there is a weak negative trend which differs slightly at different altitudes. There are however no drifts in the annual variation of water vapour from the point of view of onset of summer and winter. We compare our climatology to the reference water vapour profiles from AFGL, a free and easy accessible reference atmosphere. There are strong deviations between our observations and the reference profile, therefore we publish our climatological dataset in a table in the paper.

\section{Introduction}

Water vapour is an important greenhouse gas and a key player in the chemistry of the Earth's atmosphere. It also has an important role for the formation of noctilucent clouds (von Zahn et al., 2004), and may be subject to antropogenic effects in the upper mesosphere/lower thermosphere region (Stevens et al., 2003, 2012). For the last

\section{ACPD}

12, 31531-31560, 2012

Water vapour above ALOMAR

K. Hallgren et al.

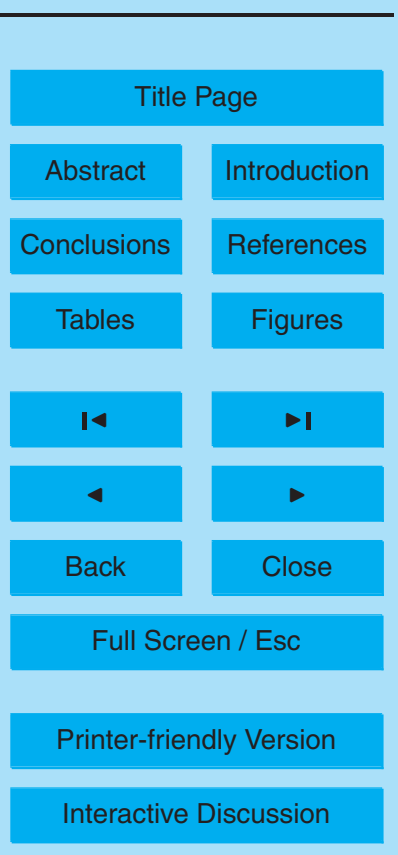


few decades it has received a lot of attention and a general picture of the distribution of water vapour in the middle atmosphere has been established (e.g. Taylor et al., 1981; Reber et al., 1993; Mote et al., 1996; Nedoluha et al., 1996; Seele and Hartogh, 1999; Urban et al., 2007). To first order water vapour is governed by a balance be5 tween vertical transport and photochemistry. The primary source of water is upwelling air through the tropical tropopause layer (Holton et al., 1995). The cold temperatures in the tropopause and the subsequent freeze-drying effect significantly reduces the water vapour mixing ratio of the upwelling air entering to 3.5-4 ppmv. Due to the oxidation of methane in the stratosphere the mixing ratio starts to increase again with altitude.

10 At an altitude of $45-50 \mathrm{~km}$ the increase levels out. Here, photodissociation caused by Solar Lyman- $\alpha$ radiation acts as a sink and the amount of water vapour is in equilibrium between different photochemical processes and vertical transport. With increasing altitude the photodissociation increases and at approximately $60-65 \mathrm{~km}$ when most of the methane has been oxidised the amount of water vapour starts to decrease (Brasseur 15 and Solomon, 1998). A secondary maximum around $65-75 \mathrm{~km}$, caused by autocatalytic processes, is present with a varying degree of strength from year-to-year (Summers et al., 1997; Seele and Hartogh, 1999; Sonnemann et al., 2005). The mixing ratio and altitude of the local maximum of this layer is however variable and could indicate a correlation to the QBO (Sonnemann et al., 2009). The mesosphere at high latitudes

20 is characterised by a strong annual variation determined by the mean transport as reported by (Nedoluha et al., 1996; Seele and Hartogh, 1999). During the summer there is a mean upward flow which transport humid air high into the atmosphere. This flow is reversed during winter which gives rise to the annual oscillation with a summer maximum.

25 With the overall picture settled, including investigations on its behavior on short timescales (e.g. Haefele et al., 2008; Sonnemann et al., 2008; Hallgren and Hartogh, 2012) the long-term evolution of water vapour in the middle atmosphere has received some attention during the last few years. Through the destruction and production processes of water vapour it directly affects the hydrogen chemistry of the middle

\section{ACPD}

12, 31531-31560, 2012

Water vapour above ALOMAR

K. Hallgren et al.

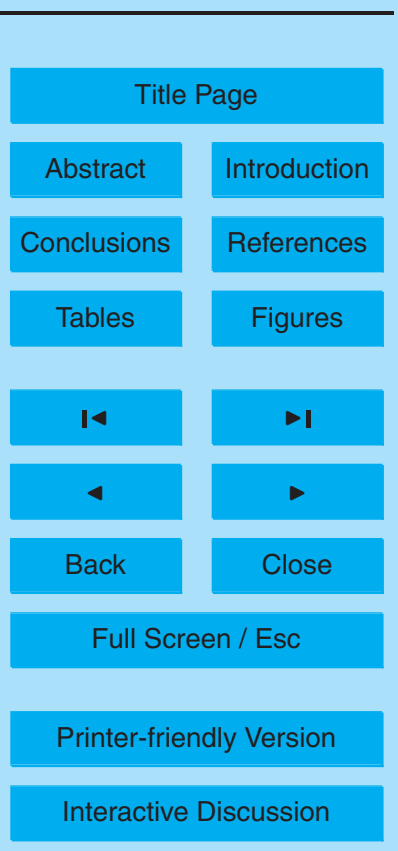


atmosphere $\left(\mathrm{HO}_{\mathrm{x}}\right.$ and $\left.\mathrm{OH}\right)$ which in turn affects the ozone chemistry (Hartogh et al., 2004, 2011a,b). The hydrogen chemistry comprises all hydrogen-bearing constituents such as $\mathrm{H}_{2} \mathrm{O}, \mathrm{H}_{2}, \mathrm{CH}_{4}$ and the $\mathrm{HO}_{\mathrm{x}}$-radicals. It is therefore important to understand its natural variability for a complete assessment of the climate. Thus, accurate and reliable 5 observations of the amounts of water vapour in the middle atmosphere are necessary. Numerous instruments, both ground-based and space-borne, observe water vapour continuously. It is therefore troubling that no conclusive results of the long-term evolution of water vapour exist. Laštovička (2009) names the long-term behaviour of water vapour as one of three current problems in understanding the middle atmosphere. Garcia et al. (2007) also investigate this issue and suggest possible solutions to the problem. They model the behaviour of water vapour since 1950 with the Whole Atmosphere Community Climate Model version 3 (WACCM3) and the obtained results do not agree with either satellite observations from the Halogen Occultation Experiment (HALOE) observations or ground-based results from a hygrometer dataset from Boulder, Colorado. On the other hand, ozone and temperature trends which also were modeled and used the same comparison agree well. The explanation for the observed discrepancies is related to the size of the datasets. The WACCM3 simulations are based on a much longer dataset compared to the observations. The hygrometer dataset goes back to 1980 whereas the HALOE dataset only dates back to the mid-nineties. This might induce a bias where low frequency cyclic variations could be interpreted as trends by short datasets. Unfortunately there is a shortage of long observational of water vapour datasets which would allow us to remove such biases. Shorter datasets are however very common and when used in comparison with reference atmospheres their differences, and similarities, can better be assessed.

The authors have identified a lack of accessible and updated reference profiles of middle atmospheric water vapour, especially concerning the polar latitudes. CIRA is a well-known and recently updated standard reference model of the atmosphere and in part III of the reference model constituent profiles were included (Chiou et al., 1996), however there is no coverage of the polar regions. Concerning reference profiles such

Water vapour above ALOMAR

K. Hallgren et al.

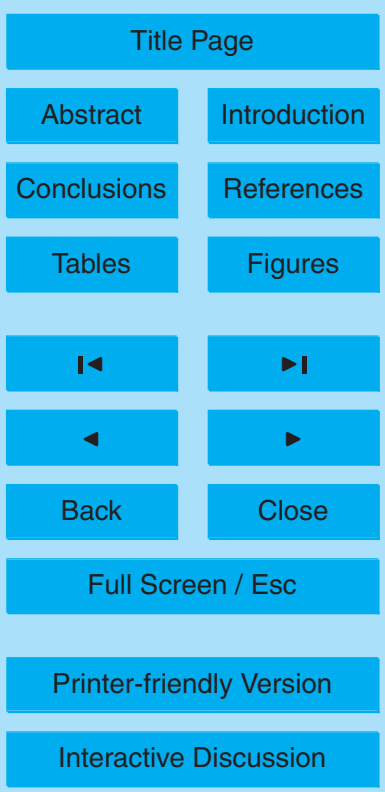


as the older US Standard Atmosphere (Minzner, 1977) and the Air Force Geophysical Laboratory (AFGL) Constituent Profiles (Anderson et al., 1986), profiles for the polar latitudes do exist and will be discussed in the last section. The aim of this paper is to address this the lack of reference profiles by making available 15 years of ground5 based observations of water vapour above the ALOMAR observatory $\left(69^{\circ} \mathrm{N}, 16^{\circ} \mathrm{E}\right)$. The measurements providing the mixing ratio profiles were carried out with microwave spectrometers detecting the rotational transition of water vapour at $22.235 \mathrm{GHz}$. Although ground-based observation of the stronger $183 \mathrm{GHz}$ line are in principle possible (Hartogh et al., 1991) the lower frequency has the advantage of being optically thinner 10 which makes it more favourable for ground-based observations (Hartogh and Jarchow, 1995; Nedoluha et al., 1996; Seele and Hartogh, 1999; Haefele et al., 2009). In addition to the presented reference profiles we will discuss the long-term behaviour of the water vapour in the middle atmosphere and compare the presented reference profile to the available water vapour profiles.

\section{Observations and retrieval}

We have been observing the $22.235 \mathrm{GHz}$ line of water vapour above ALOMAR with slightly different instrument setups since early 1996. The core, and basic technique of the instruments have however remained the same throughout the whole time, a cooled heterodyne microwave spectrometer. An overview of their differences and similarities can be seen in Table 1. The first instrument, WASPAM (Wasserdampf- und Spurengasmessungen in der Atmosphäre mit Mikrowellen) was installed at ALOMAR during autumn 1995 and while the front-end receiver of this instrument was successfully running until 2006 the back-end spectrometers has changed over the years. A complete description of the instrument and associated upgrades to the hardware can be found in Hartogh and Jarchow (1995) and Seele and Hartogh (1999). The successor instrument, cWASPAM (cooled-WASPAM) was installed in May 2008 and a detailed description for this instrument can be found in Hallgren et al. (2010). Both instruments
ACPD

12, 31531-31560, 2012

Water vapour above ALOMAR

K. Hallgren et al.

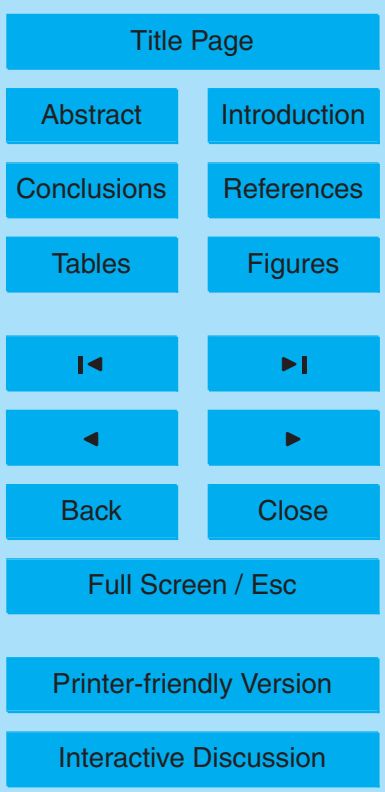

Interactive Discussion 
observe water vapour at $22.235 \mathrm{GHz}$ and employ heterodyne techniques to downconvert the incoming signal to a lower frequency for processing in a chirp transform spectrometer (CTS) (Hartogh and Hartmann, 1990; Hartogh and Jarchow, 1995; Hartogh, 1997, 1998; Villanueva and Hartogh, 2004; Villanueva et al., 2006). Apart from

5 a few years between 2002 - 2005 when a wide-band spectrometer $(180 \mathrm{MHz}$ ) was used, all CTS have been narrow-band spectrometers with $40 \mathrm{MHz}$ bandwidth. Due to the limited bandwidth of the back-end spectrometer we can only obtain vertical distribution of the water vapour above $40-45 \mathrm{~km}$. The upper limit of the profile retrieval is determined by the threshold level where Doppler broadening becomes larger than the 10 pressure broadening. For the observed water vapour line this occurs around $85 \mathrm{~km}$. In order to retrieve profile information at the uppermost altitudes the spectral resolution (channel spacing) of the spectrometer needs to be smaller than the Doppler width of the emission line, which is approximately $30 \mathrm{kHz}$ in case of the water vapour transition at $22.235 \mathrm{GHz}$. All back-ends used, except the wide-band spectrometer, have a better 15 spectral resolution than this, thus with sufficient integration time we are able to resolve the vertical distribution of water vapour up to the physically limited altitude.

Both WASPAM and cWASPAM use a hot/cold load calibration scheme in which the power of the incoming signal is compared to the well-known temperature of the calibration loads. In the case of WASPAM only the first-stage amplifier and cold load was cooled whereas in the case of cWASPAM the horn antenna and hot load are also cooled. By cooling the horn antenna the system temperature and noise are reduced and cold hot-load helps to minimise the influence of non-linearities in the system (Paganini and Hartogh, 2009).

The profiles have been retrieved using the optimal estimation method (OEM) (Rodgers, 25 1976) as described in Jarchow and Hartogh (1995, 1998); Hallgren et al. (2010). During the retrieval a background atmosphere with temperatures and pressures is needed. We use a plane-parallel atmosphere composed of 28 layers, each $2.5 \mathrm{~km}$ thick in an altitude range from 25 to $92.5 \mathrm{~km}$. However, the actual vertical resolution of the instruments depends on the signal-to-noise ratio of the instruments and varies between

Water vapour above ALOMAR

K. Hallgren et al.

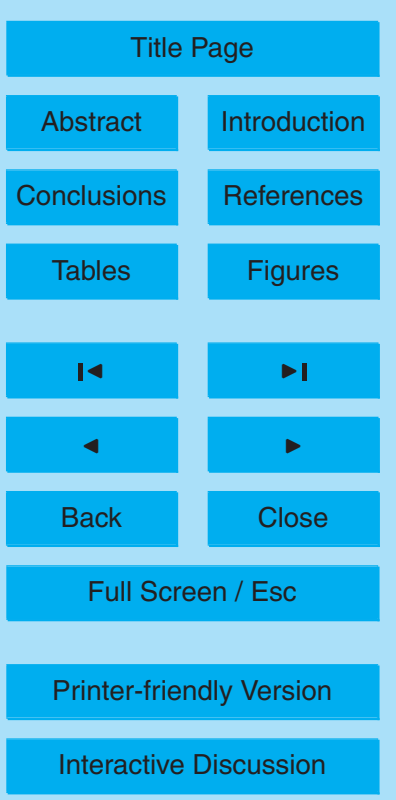


7-10 km (FWHM of the averaging kernels) (Hartogh et al., 2010; Hallgren and Hartogh, 2012).

The lower part of the temperature/pressure profile $(<55 \mathrm{~km})$ is real atmospheric data from National Centers for Environmental Prediction (NCEP) (McPherson et al., 1979).

5 This is nudged to a reference model, CIRA86 (Fleming et al., 1990), which is modified with temperatures from a falling sphere climatology from Lübken (1999) during the summer months. Thus the main part of the background used for the retrievals is identical from year-to-year. However, the year-to-year difference in the middle atmosphere is relatively small, on the order of $4-6 \mathrm{~K}$, in the upper stratosphere to middle mesosphere 10 Lübken (1999) and only affect the retrieved profile by a few percent Hallgren (2010). The total error including measurement errors lies within 10-15\%, with the larger error at the upper limit of the instruments.

Data from WASPAM were reanalysed with the updated retrieval pipeline constructed for cWASPAM. The main difference was a harmonic approach to remove baseline ripples in the spectra (Hallgren, 2010) and the filtering of spectra with too low signalto-noise ratio or systematic errors. Furthermore, in order to facilitate the comparison only the inner $40 \mathrm{MHz}$ of the wide-band CTS was used. Artifacts introduced by different baseline reduction schemes between the back-ends could therefore be minimised. Unfortunately there was a gap in the observations between 2006 and 2008 caused by the failure of the WASPAM instrument before cWASPAM1 was installed. No direct comparison between these instruments was therefore possible. However, the individual instruments have been involved in different comparison campaigns and indicate that the retrieved profiles are reliable (Straub et al., 2011).

\section{Results and discussion}

25 The full dataset plotted at four different altitudes; 50, 60, 70 and $80 \mathrm{~km}$ can be seen in Figure 1. Data-gaps shorter than 3 data-points (three weeks) have been linearly interpolated to the existing data whereas longer gaps have been marked as missing.

Water vapour above ALOMAR

K. Hallgren et al.

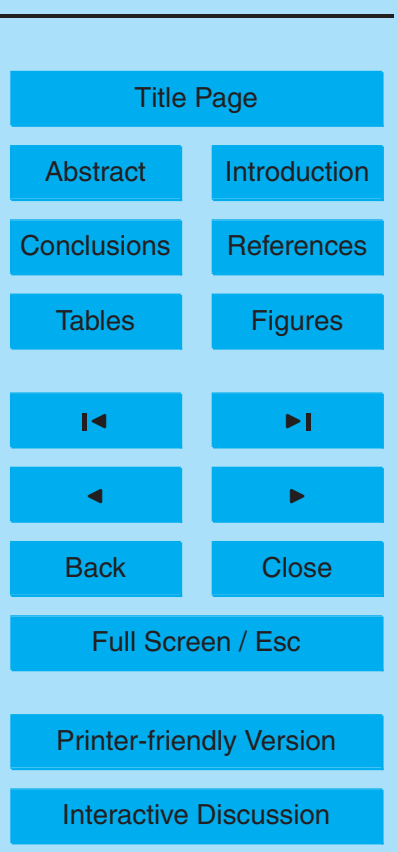


We will discuss the behaviour of water vapour over the time-period covered by our observations. Any long-term behaviour, such as net effects in the total amount of water vapour as observed by our instrument will be denoted as trends. We are aware that the dataset is limited and that this is not a complete picture of the global behaviour of 5 water vapour. Therefore the presented trends should not be interpreted as a trend from a global climate point of view. As can be seen Fig. 1 the amount of water vapour above ALOMAR during the last $15 \mathrm{yr}$ varies slightly and a clear trend is not visible. A reduction in the detected water vapour at high altitude can be seen between 2001-2003. This was a global event which also have been detected by other groups at lower latitudes, 10 e.g. Rosenlof and Reid (2008); Scherer et al. (2008). An explanation to this sudden decrease in water vapour was given by Randel et al. (2006) where they trace the decrease back to a change in the Brewer-Dobson circulation. In the years after the reduced water vapour the atmosphere has slowly recovered and amounts has increased. Around 2006 it reached approximately the same levels at high altitude as before the event. A detailed 15 discussion about the variation of water vapour above ALOMAR in relation to the solar cycle between 1996-2006 can be found in Hartogh et al. (2010) (from hereon H2010). The scope of that paper also included a comparison of how well the observed changes are resolved by the Leibniz Institute Middle Atmosphere (LIMA) model (Berger, 2008) and to correlate the variations to changes in the Solar Lyman- $\alpha$ radiation. Thus, this 20 will not be discussed here. The dataset used in $\mathrm{H} 2010$ is similar to the one presented here. In both datasets we have chosen to use an a priori profile which is a static annual mean profile of water vapour mixing ratio instead of a varying a priori. By doing this and assuming that our instrument is stable we know that all changes in the observed water vapour are results of changing water vapour mixing ratios in the atmosphere 25 and not a result of the changing a priori profile. There are however a few important differences between the datasets. Three more years of data from the new instrument have been included. Additionally, the data in $\mathrm{H} 2010$ are obtained with a $24 \mathrm{~h}$ integration smoothed with a seven day running mean. The data presented here on the other hand are obtained with $168 \mathrm{~h}$ integration and no smoothing. By using a longer integration

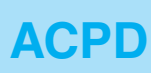

12, 31531-31560, 2012

Water vapour above ALOMAR

K. Hallgren et al.

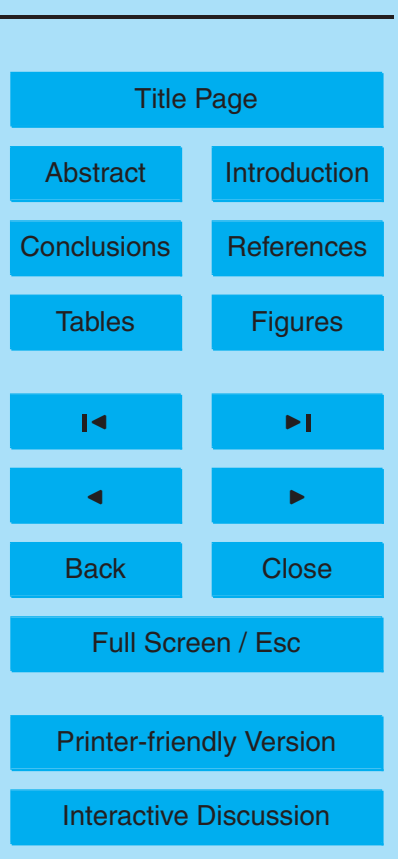

31538 
time the sensitivity of the older instrument increases significantly at high altitude. The longer integration time results in slightly higher mixing ratios during summer and lower during winter. This can be explained by the fact that the noisier the signal the more information from the a priori profile will be used and less from the actual observation.

5 As the a priori profile used is an annual mean it slightly underestimates the amount of water vapour during summer and consequently overestimates it during winter. H2010 also note that the observed amount of water vapour at high altitude by WASPAM are lower during summer and higher during winter compared to LIMA results. In the light of the reanalysed data this difference is smaller than previously thought.

10 To get a more detailed view of the long-term behaviour we look at each atmospheric layer on a seasonal basis. We focus on the two seasons with stable wind conditions, the summer and winter. The equinoxes represent a transition time between a prevailing polar-ward or equatorward wind and have not been included in this analysis. They will however be discussed later as we investigate the presence of drifts in the onset 15 of summer and winter. Figure 2 shows the trend for each layer during the summer months June, July and August (JJA) in red and winter, December, January and February (DJF) in blue. Trend is used here to mean the net behaviour spanning the complete dataset. At all altitudes there is a slight negative trend of water vapour mixing ratio. Similar to what was presented in $\mathrm{H} 2010$ for the observations as well as LIMA results the strongest trend can be found during winter at $60-70 \mathrm{~km}$. The strongest trend in the dataset is located at a lower altitude, and is weaker than in the H2010 dataset. Concerning the summer season there is almost no difference between the current dataset and the one presented in $\mathrm{H} 2010$. If we assume the years which hade reduced amounts of water vapour (2001-2003) to be an anomaly and remove them from the analysis the trend is approximately $30 \%$ weaker at high altitude (not shown). A much larger difference is present in the comparison between the datasets during winter, with the one presented in $\mathrm{H} 2010$ being almost twice as strong as the one from the current analysis. The maximum trend peaks at approximately $-0.032 \mathrm{ppmv} / \mathrm{yr}$ at $62.5 \mathrm{~km}$ altitude for the

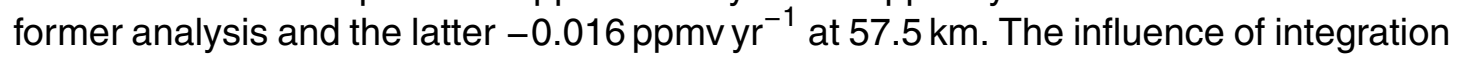

ACPD

12, 31531-31560, 2012

Water vapour above ALOMAR

K. Hallgren et al.

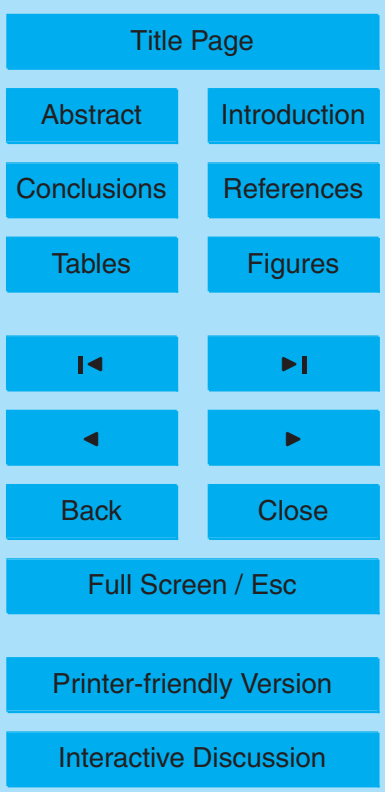


time at these altitudes is negligible which indicates that there has been an increase of water vapour in this region during the last few years. The water vapour abundance is assumed to be correlated to the amount of methane as methane is a source of water vapour in the middle atmosphere (Grygalashvyly et al., 2009; Sonnemann et al., 2012).

5 During a major part of the observational time $(1999-2008)$ the amount of methane in the atmosphere seems to have remained relatively stable as the earlier increase levelled out (Dlugokencky et al., 2003; Worthy et al., 2009). Although the changes in the amount of methane do not fully explain the behaviour we see in water vapour it can act as an indicator that transport mechanisms in the atmosphere are important

10 for the water vapour distribution. The importance of the transport mechanisms was also discussed in Randel et al. (2006); Scherer et al. (2008) and H2010 as a reason for the anomalously low amounts of water vapour in the middle atmosphere between 2001-2003. Recent results indicate that the amount of methane has started to increase again (Rigby et al., 2008; Dlugokencky et al., 2009) and although we still haven't no15 ticed any direct effect on the amount of middle atmospheric water vapour, correlating the observations of methane and water vapour could help us to further constrain their relationship and the importance of the mean atmospheric transport.

\subsection{Sudden stratospheric warmings in the dataset}

During the years covered by the dataset a number of stratospheric warmings occurred. 20 A stratospheric warming alter the dynamics in the polar atmosphere and therefore affect the water vapour mixing ratio in the middle atmosphere (e.g. Labitzke, 1972; Siskind et al., 2005; Manney et al., 2009). High temperature and (or) a high water vapour mixing ratio can substantially influence the ozone distribution by a positive feedback between the ozone dissociation frequency and the ozone mixing ratio forming 25 spots of reduced ozone mixing ratios (Sonnemann and Hartogh, 2009). An in-depth investigation using the WASPAM instrument of one warming can be found in Seele and Hartogh (2000), which covers the event in February 1998 showed that groundbased instruments have the capability to observe the effects of sudden stratospheric

Water vapour above ALOMAR

K. Hallgren et al.

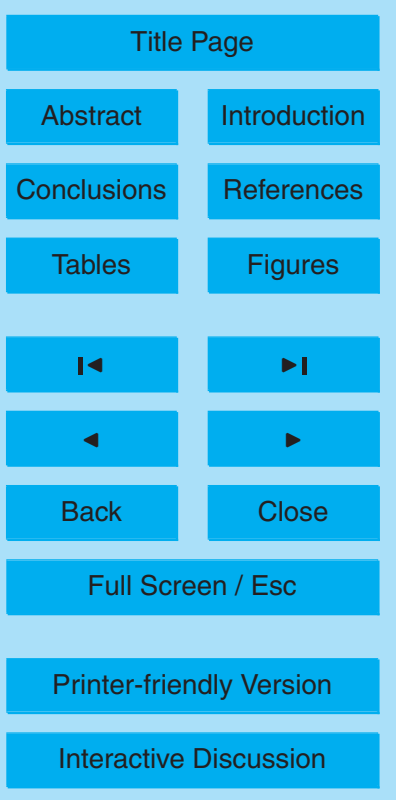


warmings on the water vapour mixing ratio. Later papers by for example Flury et al. (2009); Straub et al. (2012) has proven the possibility to backtrace the transport patterns of trace gases during the event.

The 1998 warming and later events with the corresponding increase in the amount 5 of water vapour in the lower layers can be seen in the dataset depicted in Fig. 1 as sharp and usually short term increases of water vapour during the winter. The 1998 warming was a minor warming from the point of view of how it affected the polar vortex. However, it had a large effect on the stratospheric temperature (von Zahn et al., 1998). Temperatures taken from NCEP indicate that this warming increased the stratospheric 10 temperatures by approximately $20 \mathrm{~K}$. We have compared how the 1998 warming affected the water vapour compared to the one in January 2009. The latter warming was a major warming with a complete and irreversible break-up of the polar vortex. During the 1998 warming a strong temperature increase in the stratopause region can be seen $(\approx 270 \mathrm{~K}$ at $40 \mathrm{~km})$. It is however localised in altitude and almost no increase at all can be seen at $30 \mathrm{~km}$. For 2009 the temperature increase is smaller but affects a vertically elongated region and has a pillar-like shape, from the stratopause down to approximately $30 \mathrm{~km}$. Opposite to what would be expected from the behaviour of the temperatures, the 2009 warming caused a strong increase in water vapour at the 60 and $70 \mathrm{~km}$ layer while the warming 1998 mainly affect the 50 and $60 \mathrm{~km}$ layer. Thus the results indicate that the water vapour mixing ratio is controlled by a separate process than the temperature. This claim is further strengthened by the fact that during the warming in January 2009 as well as during another warming in January 2010 the increase in water vapour predates the increase in temperature in the NCEP data by at least a day. This is however not seen in the 1998 warming. Although we have observational data of many sudden stratospheric warmings we cannot draw any conclusion about a typical behaviour in the water vapour dynamics during these events.

\section{ACPD}

12, 31531-31560, 2012

Water vapour above ALOMAR

K. Hallgren et al.

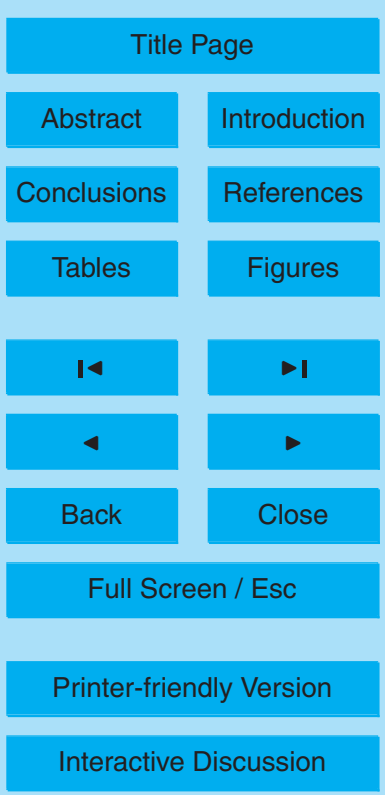




\subsection{Yearly mean middle atmospheric water vapour above ALOMAR}

In order to better assess the yearly variation of water vapour above ALOMAR, data from all years were averaged to create a mean year presented in Fig. 3 . The annual variation with a maximum during summer and minimum during winter is clearly visible, 5 as well as the secondary maximum mentioned above. Table 2 present the averaged dataset used in producing the figure. Figure 4 shows the same data but for four separate layers; $50,60,70$ and $80 \mathrm{~km}$. The variability of each bin is plotted as a dotted line above and below the mean (solid line). The variability of water vapour in the two lower altitude layers (50 and $60 \mathrm{~km}$ ) has a maximum during winter whereas the opposite is true for the higher altitudes. This is to be expected as the stratosphere in the northern hemisphere is very unstable during winter and can be characterised by a high degree of variability (Shepherd, 2000). The opposite is true for the upper layers, which have a lower variability in general, and where the maximal variation can be found during summer. If we exclude the data from the years with anomalously low amounts of water vapour (2001-2003) the variability at $80 \mathrm{~km}$ decreases by $20 \%$, whereas there is almost no difference at $70 \mathrm{~km}$.

The time of the year when the amount of water vapour starts to increase and decrease in the upper regions is well defined. We will from hereon denote the period with a stable high amount of water vapour as summer, and the positive and negative transition periods as onset of summer and onset of winter respectively. The variability during onset of summer and winter is small which indicates that this annual behaviour is relatively stable. At $70 \mathrm{~km}$ the time of the year of the maximum gradient of water vapour varies over the last 15 years by no more than 6 weeks and the maximum decreasing gradient is even more stable, the variability here is approximately four weeks. 25 To investigate if there is a shift in the onset of summer and winter we use two methods. In the first case we study if there is a shift in time when the amount of water vapour at $70 \mathrm{~km}$ exceeds $5 \mathrm{ppmv}$ and in the second case we investigate the trend of the average amount of water vapour for each day between the day-of-year 100-120 (roughly
Water vapour above ALOMAR

K. Hallgren et al.

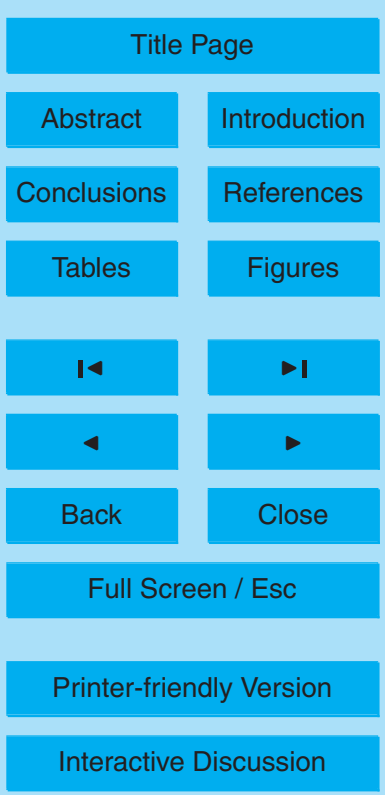

Interactive Discussion 
corresponding to the first 3 weeks in April). Both methods indicate a slight trend towards a later onset of summer. It is however not significant and the drift could be a bias effect influenced by the overall, negative trend of water vapour. A similar study was conducted for the winter transition and here no drift at all could be found. The strong 5 annual variation is less pronounced at the lower altitudes, 50 and $60 \mathrm{~km}$. These layers are instead better described as having a relatively stable amount of water vapour throughout the year. A slightly skewed annual variability do however seem to be present in the $60 \mathrm{~km}$ layer. Here a slightly positive gradient is present from approximately early April to early September where the amount of water vapour abruptly starts to decrease.

10 As mentioned above the starting time for the increase of water vapour is in early April above the $60 \mathrm{~km}$ layer and it arrives later in the year with increasing altitude. The gradient gets steeper as well with increasing altitude, and the most prominent onset can be found at $80 \mathrm{~km}$, the uppermost layer. While the behaviour is almost annually symmetric at $80 \mathrm{~km}$ there is a slight asymmetry at $70 \mathrm{~km}$ and even more so at the $60 \mathrm{~km}$ level. 15 The increasing gradient is weaker but the time of increase lasts longer and shows a very strong negative gradient in the fall. This behaviour is however not visible at the lowermost layer. At $80 \mathrm{~km}$ the negative gradient starts already in the end of July. At $70 \mathrm{~km}$ the maximum value of the water vapour ratio persists two weeks longer and at $60 \mathrm{~km}$ the decrease in water vapour is not visible until September, however then with a very steep gradient.

Although the established reference models only contain a summer and winter version, we compare them to our results in order to evaluate how well they agree. In the Figs. $4 a$ and $b$ the profile obtained from our observations can be seen in comparison with the Air Force Geophysics Laboratory (AFGL) Atmospheric Constituent Profiles for a subarctic $\left(60^{\circ} \mathrm{N}\right)$ location. The AFGL profiles are available for summer and winter conditions and are presented in their original form. Thus we have not convolved them with the sensitivity profile of our instrument. To construct the summer and winter conditions from our observations we have used the mean of the three summer (June, July, and August) and winter (December, January, and February) months respectively.

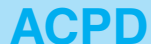

12, 31531-31560, 2012

Water vapour above ALOMAR

K. Hallgren et al.

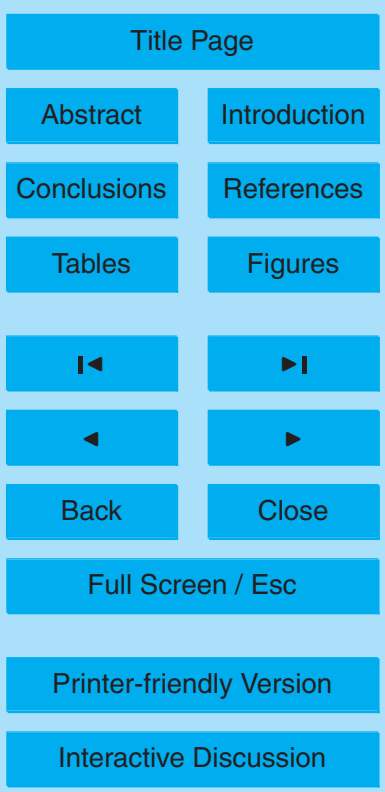


Figure $4 \mathrm{a}$ shows the summer (JJA) conditions and in Fig. 4b the winter (DJF) condition comparison can be seen. The annual variation seen in Fig. 3 is evident in the large difference in the profile between summer and winter conditions, especially at high altitude. The annual variation is not present in the AFGL profiles, there is in fact 5 no difference between the summer and winter AFGL profiles above $30 \mathrm{~km}$. In general the AFGL reference profile underestimate the amount of water vapour over the whole observed range. Since there is less water vapour in the atmosphere during winter than summer the overall agreement is better. Additionally the lack of variability, seasonal or vertical, in the AFGL profiles do not mimic the variable atmosphere very well.

\section{Conclusions}

We have compiled a dataset spanning $15 \mathrm{yr}$ (approximately $12 \mathrm{yr}$ of effective observations) of middle atmospheric water vapour from ALOMAR into a vertical reference profile covering a full year with a 7-day interval. The result is presented in Figs. 1, 3 and 4. The large dataset also allowed us to investigate the long-term behaviour of wa15 ter vapour at the location. In general the observed water vapour levels indicate a slight decrease, although the result at high altitude is biased by a global reduction of water vapour in 2001. We investigated the trend on both a seasonal and altitude basis and the strongest trend can be found around $60 \mathrm{~km}$ during winter (December-February). The most prominent feature in the dataset is the well-known annual variation. The time of transition between summer and winter for this variation was investigated and although there is a slight indication of a later onset of summer it is not statistically significant. For winter no drifts in the transition period was found.

A secondary maximum in the vertical distribution is present during the summer months, although its behaviour is less stable than the annual variation. Some years show a stronger and more persistent secondary maximum compared to other years. Nevertheless it is stable enough to be clearly visible in the average climatology for the whole dataset. The year-to-year variability is larger during winter for the lower range of

\section{ACPD}

12, 31531-31560, 2012

Water vapour above ALOMAR

K. Hallgren et al.

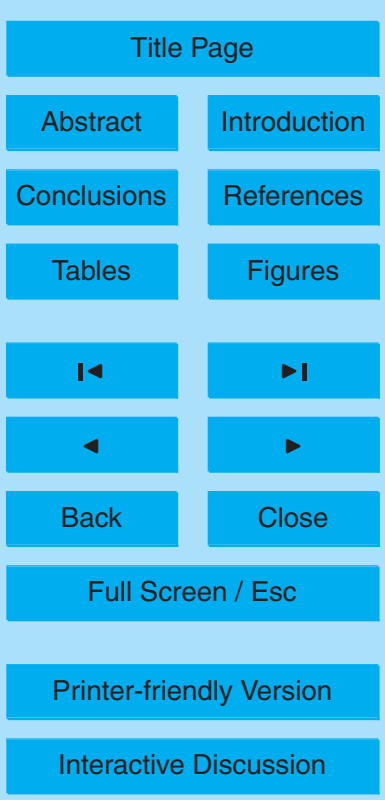


observations whereas the opposite is true for the higher altitudes, which show a larger variability during summer.

The retrieved profiles were compared to the AFGL constituent reference profile and large differences where found especially during summer. In general the AFGL profiles 5 underestimate the amounts of water vapour over the whole observed altitude range. In addition the reference profile fail to reproduce the vertical variability over the year.

Acknowledgements. This work was supported by the German Research Community DFG, grant HA-3261/7-1. The authors would like to thank the staff at ALOMAR for their support in administering the instrument. We are also thankful for the work done by the Atmospheric and 10 Dynamics branch at NASA Goddard Space Center in producing and making the NCEP data available through their automailer system.

The service charges for this open access publication have been covered by the Max Planck Society.

\section{References}

Anderson, G. P., Clough, S. A., Kneizys, F. X., Chetwynd, J. H., and Shettle, E. P.: Atmospheric Constituent Profiles (0-120 km), Environmental Research paper no. 954 AFGL-TR-86-0-10, Air Force Geophysics Laboratory, 1986. 31535

Berger, U.: Modeling of middle atmosphere dynamics with LIMA, J. Atmos. Sol.-Terr. Phys., 70, 1170-1200, doi:10.1016/j.jastp.2008.02.004, 2008. 31538

Brasseur, G. and Solomon, S.: Aeronomy of the middle atmosphere, D. Reidel Publishing Company, 1998. 31533

Chiou, E. W., Remsberg, E. E., Rodgers, C. D., Munro, R., Bevilacqua, R. M., McCormick, M. P., and Russell, J. M.: Proposed reference model for middle atmosphere water vapor,

Dlugokencky, E. J., Houweling, S., Bruhwiler, L., Masarie, K. A., Lang, P. M., Miller, J. B., and Tans, P. P.: Atmospheric methane levels off: Temporary pause or a new steady-state?, Geophys. Res. Lett., 30, 1992, doi:10.1029/2003GL018126, 2003.

\section{ACPD}

12, 31531-31560, 2012

Water vapour above ALOMAR

K. Hallgren et al.

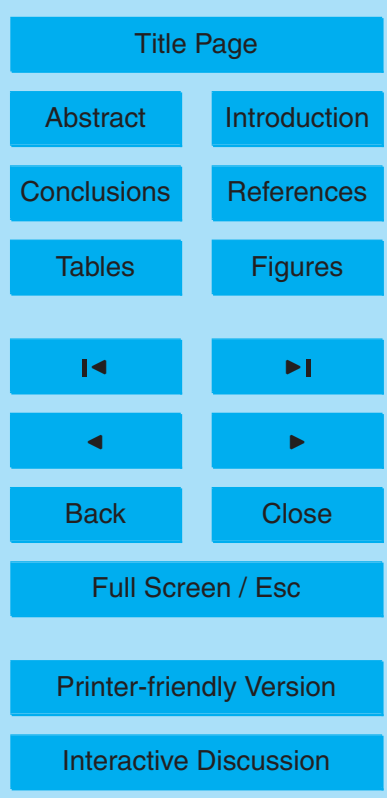


Dlugokencky, E. J., Bruhwiler, L., White, J. W. C., Emmons, L. K., Novelli, P. C., Montzka, S. A., Masarie, K. A., Lang, P. M., Crotwell, A. M., Miller, J. B., and Gatti, L. V.: Observational constraints on recent increases in the atmospheric $\mathrm{CH}_{4}$ burden, Geophys. Res. Lett., 36, L18803, doi:10.1029/2009GL039780, 2009. 31540

5 Fleming, E. L., Chandra, S., Barnett, J., and Corney, M.: Zonal mean temperature, pressure, zonal wind and geopotential height as functions of latitude, Adv. Space Res., 10, 11-59, doi:10.1016/0273-1177(90)90386-E, 1990. 31540

Flury, T., Hocke, K., Haefele, A., Kämpfer, N., and Lehmann, R.: Ozone depletion, water vapor increase, and PSC generation at midlatitudes by the 2008 major stratospheric warming, J. Geophys. Res. Atmos., 114, D18302, doi:10.1029/2009JD011940, 2009. 31537 31541

Garcia, R. R., Marsh, D. R., Kinnison, D. E., Boville, B. A., and Sassi, F.: Simulation of secular trends in the middle atmosphere, 1950-2003, J. Geophys. Res. Atmos., 112, D09301, doi:10.1029/2006JD007485, 2007. 31534

15 Grygalashvyly, M., Sonnemann, G. R., and Hartogh, P.: Long-term behavior of the concentration of the minor constituents in the mesosphere - a model study, Atmos. Chem. Phys., 9, 2779-2792, doi:10.5194/acp-9-2779-2009, 2009. 31540

Haefele, A., Hocke, K., Kämpfer, N., Keckhut, P., Marchand, M., Bekki, S., Morel, B., Egorova, T., and Rozanov, E.: Diurnal changes in middle atmospheric $\mathrm{H}_{2} \mathrm{O}$ and $\mathrm{O}_{3}$ : Observations in the Alpine region and climate models, J. Geophys. Res. Atmos., 113, D17303, doi:10.1029/2008JD009892, 2008. 31533

Haefele, A., De Wachter, E., Hocke, K., Kämpfer, N., Nedoluha, G. E., Gomez, R. M., Eriksson, P., Forkman, P., Lambert, A., and Schwartz, M. J.: Validation of ground-based microwave radiometers at $22 \mathrm{GHz}$ for stratospheric and mesospheric water vapor, J. Geophys. Res. Atmos., 114, D23305, doi:10.1029/2009JD011997, 2009. 31535

Hallgren, K.: Mesospheric water vapor - Variability at different timescales observed by groundbased microwave spectroscopy, Ph.D. thesis, Universität Rostock, 2010. 31537

Hallgren, K. and Hartogh, P.: First detection of tidal behaviour in polar mesospheric water vapour by ground based microwave spectroscopy, Atmos. Chem. Phys., 12, 3753-3759, doi:10.5194/acp-12-3753-2012, 2012. 31533, 31537

Hallgren, K., Hartogh, P., and Jarchow, C.: A New, High-performance, Heterodyne Spectrometer for Ground-based Remote Sensing of Mesospheric Water Vapour, 19, 569-578, World Scientific Publishing Co., 2010. 31535, 31536

Water vapour above ALOMAR

K. Hallgren et al.

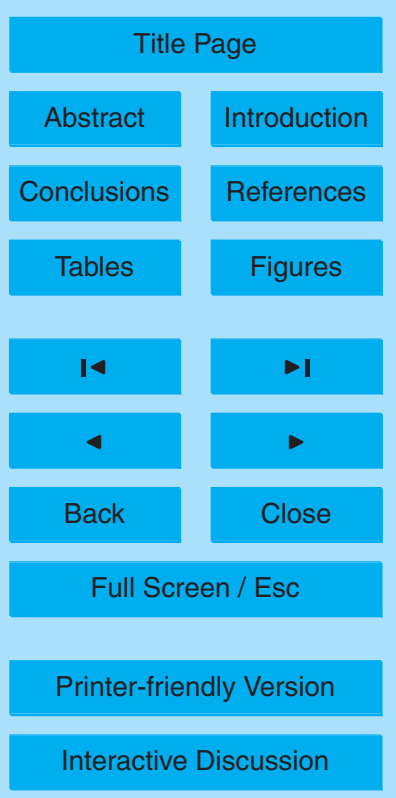


Hartogh, P.: Present and future chirp transform spectrometers for microwave remote sensing, in: Society of Photo-Optical Instrumentation Engineers (SPIE) Conference Series, edited by: Fujisada, H., vol. 3221 of Presented at the Society of Photo-Optical Instrumentation Engineers (SPIE) Conference, 328-339, 1997. 31536

5 Hartogh, P.: High-resolution chirp transform spectrometer for middle atmospheric microwave sounding, in: Satellite Remote Sensing of Clouds and Atmosphere II, edited by: Haigh, J. D., vol. 3220 of Proc. SPIE, 115-124, 1998. 31536

Hartogh, P. and Hartmann, G. K.: A high-resolution chirp transform spectrometer for microwave measurements, Meas. Sci. Technol., 1, 592-595, 1990. 31536

10 Hartogh, P. and Jarchow, C.: Groundbased detection of middle atmospheric water vapor, in: Global Process Monitoring and Remote Sensing of Ocean and Sea Ice, EUROPTO-Series 2586, 188-195, SPIE, Bellingham, 1995. 31535, 31536

Hartogh, P., Hartmann, G. K., and Zimmerman, P.: Simultaneous Water Vapour And Ozone Measurements with Millimeterwaves In The Stratosphere And Mesosphere, in: IEEE Catalog

15 Number 91CH2971-0, vol. 1, 227-230, 1991. 31535

Hartogh, P., Jarchow, C., Sonnemann, G. R., and Grygalashvyly, M.: On the spatiotemporal behavior of ozone within the upper mesosphere/mesopause region under nearly polar night conditions, J. Geophys. Res. Atmos., 109, D18303, doi:10.1029/2004JD004576, 2004. 31534

20 Hartogh, P., Sonnemann, G. R., Grygalashvyly, M., Song, L., Berger, U., and Lübken, F.: Water vapor measurements at ALOMAR over a solar cycle compared with model calculations by LIMA, J. Geophys. Res. Atmos., 115, D00l17, doi:10.1029/2009JD012364, 2010. 31537, 31538

Hartogh, P., Jarchow, C., Sonnemann, G. R., and Grygalashvyly, M.: Ozone distribution in the middle latitude mesosphere as derived from microwave measurements at Lindau $\left(51.66^{\circ} \mathrm{N}\right.$, $10.13^{\circ}$ E), J. Geophys. Res. Atmos., 116, D04305, doi:10.1029/2010JD014393, 2011a. 31534

Hartogh, P., Sonnemann, G. R., Grygalashvyly, M., and Jarchow, C.: Ozone trends in the mid-latitude stratopause region based on microwave measurements at Lindau $\left(51.66^{\circ} \mathrm{N}\right.$, $\left.10.13^{\circ} \mathrm{E}\right)$, the ozone reference model, and model calculations, Adv. Space Res., 47, 19371948, doi:10.1016/j.asr.2011.01.010, 2011b. 31534

\section{ACPD}

12, 31531-31560, 2012

\section{Water vapour above ALOMAR}

K. Hallgren et al.

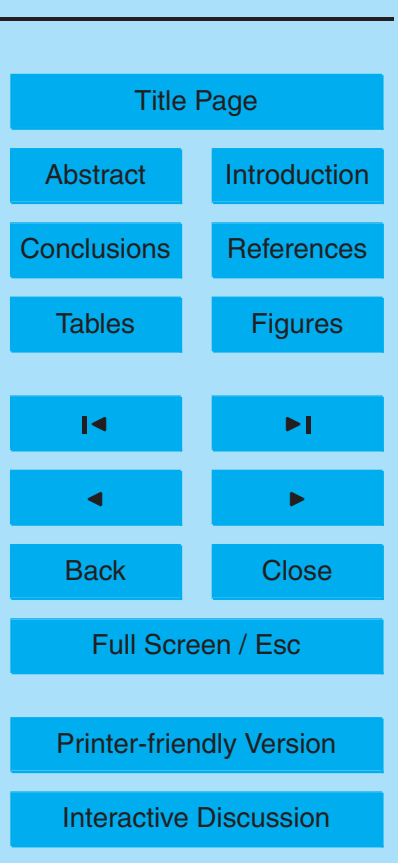


Holton, J. R., Haynes, P. H., Mclntyre, M. E., Douglass, A. R., Rood, R. B., and Pfister, L.: Stratosphere-troposphere exchange, Rev. Geophys., 33, 403-439, doi:10.1029/95RG02097, 1995. 31533

Jarchow, C. and Hartogh, P.: Retrieval of data from ground-based microwave sensing of the

5 middle atmosphere: Comparison of two inversion techniques, in: Global Process Monitoring and Remote Sensing of Ocean and Sea Ice, EUROPTO-Series 2586, 196-205, SPIE, Bellingham, 1995. 31536

Jarchow, C. and Hartogh, P.: Analysis of forward models using the singular value decomposition algorithm., in: Satellite Remote Sensing of Clouds and the Atmosphere II, edited by: Haigh, J. D., vol. 3220 of Proc. SPIE, 163-173, SPIE, London, 1998. 31536

Labitzke, K.: Temperature Changes in the Mesosphere and Stratosphere Connected with Circulation Changes in Winter., J. Atmos. Sci., 29, 756-766, doi:10.1175/15200469(1972)029<0756:TCITMA>2.0.CO;2, 1972. 31540

Laštovička, J.: Global pattern of trends in the upper atmosphere and ionosphere: Recent 15 progress, J. Atmos. Sol.-Terr. Phys., 71, 1514-1528, doi:10.1016/j.jastp.2009.01.010, 2009. 31534

Lübken, F.: Thermal structure of the arctic summer mesosphere, J. Geophys. Res., 104, 91359150, doi:10.1029/1999JD900076, 1999. 31537

Manney, G. L., Harwood, R. S., MacKenzie, I. A., Minschwaner, K., Allen, D. R., Santee, M. L., Walker, K. A., Hegglin, M. I., Lambert, A., Pumphrey, H. C., Bernath, P. F., Boone, C. D., Schwartz, M. J., Livesey, N. J., Daffer, W. H., and Fuller, R. A.: Satellite observations and modeling of transport in the upper troposphere through the lower mesosphere during the 2006 major stratospheric sudden warming, Atmos. Chem. Phys., 9, 4775-4795, doi:10.5194/acp-9-4775-2009, 2009. 31540

McPherson, R. D., Bergman, K. H., Kistler, R. E., Rasch, G. E., and Gordon, D. S.: The NMC Operational Global Data Assimilation System, Mon. Weather Rev., 107, 1445-1461, doi:10.1175/1520-0493(1979)107<1445:TNOGDA>2.0.CO;2, 1979. 31537

Minzner, R. A.: The 1976 Standard Atmosphere and its relationship to earlier standards, Rev. Geophys. Space Phys., 15, 375-384, 1977. 31535

so Mote, P. W., Rosenlof, K. H., Mclntyre, M. E., Carr, E. S., Gille, J. C., Holton, J. R., Kinnersley, J. S., Pumphrey, H. C., Russell, III, J. M., and Waters, J. W.: An atmospheric tape recorder: The imprint of tropical tropopause temperatures on stratospheric water vapor, J. Geophys. Res., 101, 3989-4006, doi:10.1029/95JD03422, 1996. 31533

\section{ACPD}

12, 31531-31560, 2012

Water vapour above ALOMAR

K. Hallgren et al.

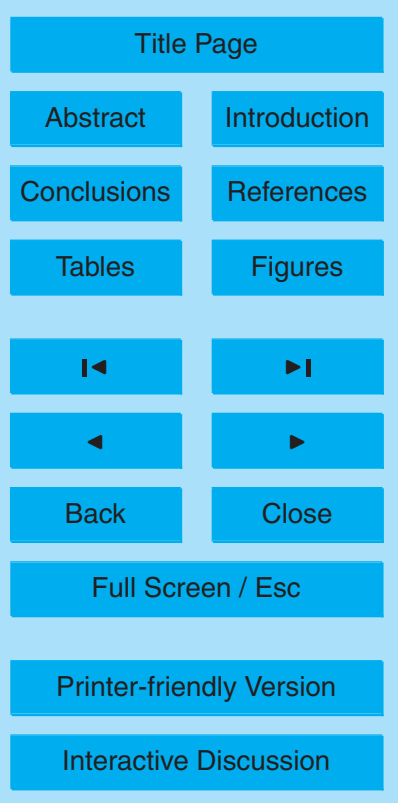


Nedoluha, G. E., Bevilacqua, R. M., Michael Gomez, R., Waltman, W. B., Hicks, B. C., Thacker, D. L., and Andrew Matthews, W.: Measurements of water vapor in the middle atmosphere and implications for mesospheric transport, J. Geophys. Res., 101, 21183-21194, doi:10.1029/96JD01741, 1996. 31533, 31535

5 Paganini, L. and Hartogh, P.: Analysis of nonlinear effects in microwave spectrometers, J. Geophys. Res. Atmos., 114, D13305, doi:10.1029/2008JD011141, 2009. 31536

Randel, W. J., Wu, F., Vömel, H., Nedoluha, G. E., and Forster, P.: Decreases in stratospheric water vapor after 2001: Links to changes in the tropical tropopause and the BrewerDobson circulation, J. Geophys. Res. Atmos., 111, D12312, doi:10.1029/2005JD006744, 10 2006. 31538,31540

Reber, C. A., Trevathan, C. E., McNeal, R. J., and Luther, M. R.: The Upper Atmosphere Research Satellite (UARS) mission, J. Geophys. Res., 98, 10643, doi:10.1029/92JD02828, 1993. 31533

Rigby, M., Prinn, R. G., Fraser, P. J., Simmonds, P. G., Langenfelds, R. L., Huang, J., Cunnold, 15 D. M., Steele, L. P., Krummel, P. B., Weiss, R. F., O'Doherty, S., Salameh, P. K., Wang, H. J., Harth, C. M., Mühle, J., and Porter, L. W.: Renewed growth of atmospheric methane, Geophys. Res. Lett., 35, doi:10.1029/2008GL036037, 2008. 31540

Rodgers, C. D.: Retrieval of Atmospheric Temperature and Composition From Remote Measurements of Thermal Radiation, Rev. Geophys. Space Phys., 14, 609-624, doi:10.1029/RG014i004p00609, 1976. 31536

Rosenlof, K. H. and Reid, G. C.: Trends in the temperature and water vapor content of the tropical lower stratosphere: Sea surface connection, J. Geophys. Res. Atmos., 113, doi:10.1029/2007JD009109, 2008. 31538

Scherer, M., Vömel, H., Fueglistaler, S., Oltmans, S. J., and Staehelin, J.: Trends and variability of midlatitude stratospheric water vapour deduced from the re-evaluated Boulder balloon series and HALOE, Atmos. Chem. Phys., 8, 1391-1402, doi:10.5194/acp-8-1391-2008, 2008. 31538, 31540

Seele, C. and Hartogh, P.: Water vapor of the polar middle atmosphere: Annual variation and summer mesosphere conditions as observed by ground-based microwave spectroscopy., Geophys. Res. Lett., 26, 1517-1520, 1999. 31533, 31535

Seele, C. and Hartogh, P.: A case study on middle atmospheric water vapor transport during the February 1998 stratospheric warming, Geophys. Res. Lett., 26, 3309-3312, 2000. 31540

Water vapour above ALOMAR

K. Hallgren et al.

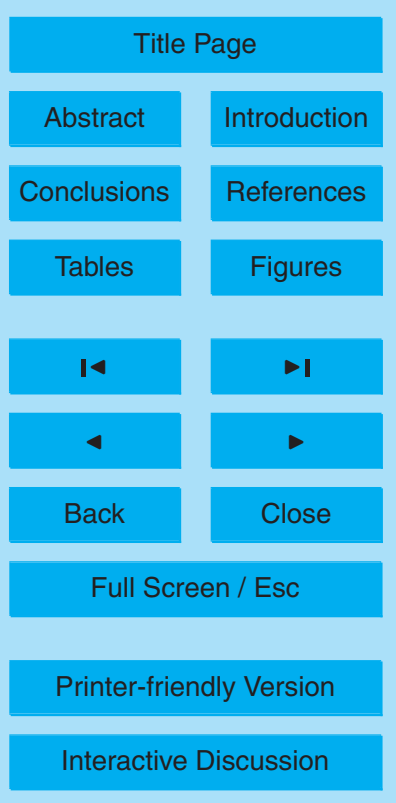


Shepherd, T. G.: The middle atmosphere, J. Atmos. Sol.-Terr. Phys., 62, 1587-1601, doi:10.1016/S1364-6826(00)00114-0, 2000. 31542

Siskind, D. E., Coy, L., and Espy, P.: Observations of stratospheric warmings and mesospheric coolings by the TIMED SABER instrument, Geophys. Res. Lett., 32, L09804,

5 doi:10.1029/2005GL022399, 2005. 31540

Sonnemann, G. R. and Hartogh, P.: Upper stratospheric ozone decrease events due to a positive feedback between ozone and the ozone dissociation rate, Nonlin. Processes Geophys., 16, 409-418, doi:10.5194/npg-16-409-2009, 2009. 31540

Sonnemann, G. R., Grygalashvyly, M., and Berger, U.: Autocatalytic water vapor production as a source of large mixing ratios within the middle to upper mesosphere, J. Geophys. Res. Atmos., 110, D15303, doi:10.1029/2004JD005593, 2005. 31533

Sonnemann, G. R., Hartogh, P., Grygalashvyly, M., Li, S., and Berger, U.: The quasi 5-day signal in the mesospheric water vapor concentration at high latitudes in 2003-a comparison between observations at ALOMAR and calculations, J. Geophys. Res. Atmos., 113, D04101, doi:10.1029/2007JD008875, 2008. 31533

Sonnemann, G. R., Hartogh, P., Li, S., Grygalashvyly, M., and Berger, U.: A QBO-signal in mesospheric water vapor measurements at ALOMAR $\left(69.29^{\circ} \mathrm{N}, 16.03^{\circ} \mathrm{E}\right)$ and in model calculations by LIMA over a solar cycle, Atmos. Chem. Phys. Discussions, 9, 883-903, doi:10.5194/acpd-9-883-2009, 2009. 31533

20 Sonnemann, G. R., Hartogh, P., Berger, U., Lübken, F.-J., and Grygalashvyly, M.: Anthropogenic effects on the distribution of minor chemical constituents in the mesosphere/lower thermosphere - A model study, Adv. Space Res., 50, 598-618, doi:10.1016/j.asr.2012.05.016, 2012. 31540

Stevens, M. H., Gumbel, J., Englert, C. R., Grossmann, K. U., Rapp, M., and Hartogh, P.: Polar mesospheric clouds formed from space shuttle exhaust, Geophys. Res. Lett., 30, 1546, doi:10.1029/2003GL017249, 2003. 31532

Stevens, M. H., Lossow, S., Fiedler, J., Baumgarten, G. Luebken, F.-J., Hallgren, K., Hartogh, P., Randall, C. E., Lumpe, J. D., Bailey, S. M., Niciejewski, R., Meier, R. R., Plane, J. M. C., Kochenash, A., Murtagh, D. P., and Englert, C. R.: Bright polar mesospheric clouds formed by main engine exhaust from the space shuttle's final launch, J. Geophys. Res., 117, D19206, doi:10.1029/2012JD017638, 2012. 31532

Straub, C., Murk, A., Kämpfer, N., Golchert, S. H. W., Hochschild, G., Hallgren, K., and Hartogh, P.: ARIS-Campaign: intercomparison of three ground based $22 \mathrm{GHz}$ radiometers for middle

Water vapour above ALOMAR

K. Hallgren et al.

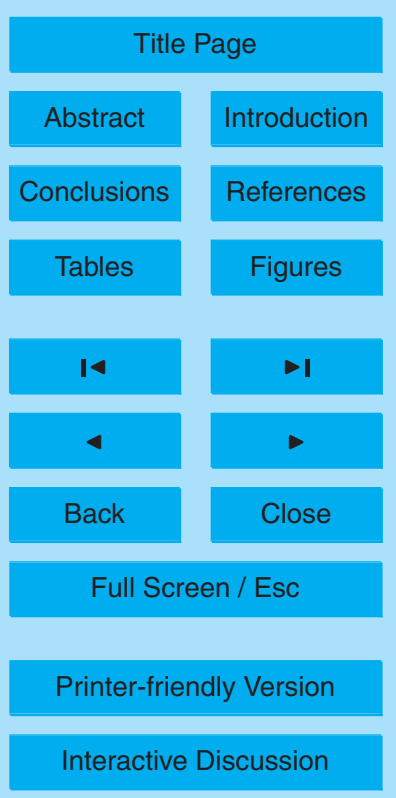

Interactive Discussion 
atmospheric water vapor at the Zugspitze in winter 2009, Atmos. Meas. Tech., 4, 1979-1994, doi:10.5194/amt-4-1979-2011, 2011. 31537

Straub, C., Tschanz, B., Hocke, K., Kämpfer, N., and Smith, A. K.: Transport of mesospheric $\mathrm{H}_{2} \mathrm{O}$ during and after the stratospheric sudden warming of January 2010: observation 5 and simulation, Atmos. Chem. Phys., 12, 5413-5427, doi:10.5194/acp-12-5413-2012, 2012. 31541

Summers, M. E., Conway, R. R., Siskind, D. E., Stevens, M. H., Offermann, D., Riese, M., Preusse, P., Strobel, D. F., and Russell III, J. M.: Implications of Satellite OH Observations for Middle Atmospheric H2O and Ozone, Science, 277, 1967-1970, doi:10.1126/science.277.5334.1967, 1997. 31533

Taylor, F. W., Barnett, J. J., Colbeck, I., Jones, R. L., Rodgers, C. D., Wale, M. J., and Williamson, E. J.: Performance and early results from the Stratospheric and Mesospheric Sounder/SAMS/on Nimbus 7, Adv. Space Res., 1, 261-265, doi:10.1016/02731177(81)90068-5, 1981. 31533

15 Urban, J., Lautié, N., Murtagh, D., Eriksson, P., Kasai, Y., Loßow, S., Dupuy, E., de La Noë, J., Frisk, U., Olberg, M., Le Flochmoën, E., and Ricaud, P.: Global observations of middle atmospheric water vapour by the Odin satellite: An overview, Planet. Space Sci., 55, 10931102, doi:10.1016/j.pss.2006.11.021, 2007. 31533

Villanueva, G. and Hartogh, P.: The High Resolution Chirp Transform Spectrometer for the

20 Sofia-Great Instrument, Experimental Astronomy, 18, 77-91, doi:10.1007/s10686-005-90043, 2004. 31536

Villanueva, G., Hartogh, P., and Reindl, L.: A digital dispersive matching network for SAW devices in chirp transform spectrometers, IEEE Trans. Microw. Theory Techn., 54, 1415-1424, doi:10.1109/TMTT.2006.871244, 2006. 31536

von Zahn, U., Fiedler, J., Naujokat, B., Langematz, U., and Krüger, K.: A note on record-high temperatures at the northern polar stratopause in winter 1997/98, Geophys. Res. Lett., 25, 4169-4172, doi:10.1029/1998GL900091, 1998. 31541

von Zahn, U., Baumgarten, G., Berger, U., Fiedler, J., and Hartogh, P.: Noctilucent clouds and the mesospheric water vapour: the past decade, Atmos. Chem. Phys., 4, 2449-2464, doi:10.5194/acp-4-2449-2004, 2004. 31532

Worthy, D. E. J., Chan, E., Ishizawa, M., Chan, D., Poss, C., Dlugokencky, E. J., Maksyutov, S., and Levin, I.: Decreasing anthropogenic methane emissions in Europe and Siberia inferred

Water vapour above ALOMAR

K. Hallgren et al.

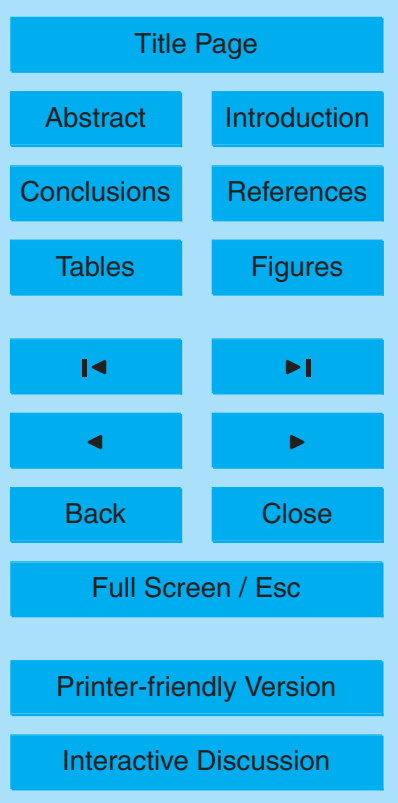

Interactive Discussion 
from continuous carbon dioxide and methane observations at Alert, Canada, J. Geophys.

Res. Atmos., 114, D10301, doi:10.1029/2008JD011239, 2009. 31540

\section{ACPD}

12, 31531-31560, 2012

\section{Water vapour above ALOMAR}

K. Hallgren et al.
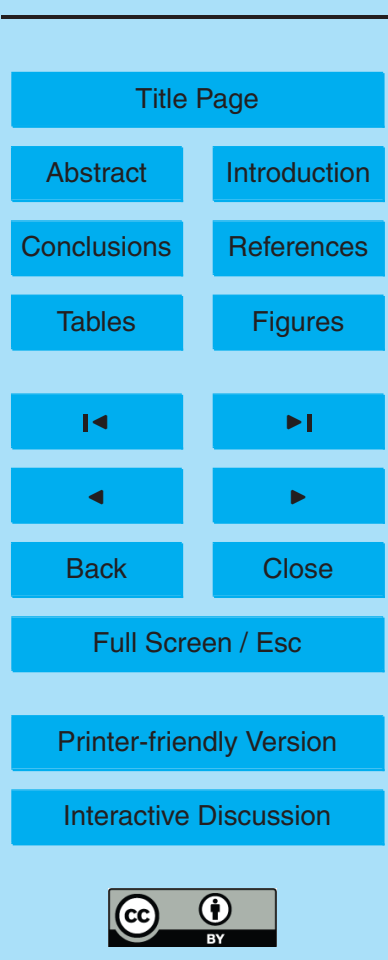


\section{ACPD}

12, 31531-31560, 2012

\section{Water vapour above ALOMAR}

K. Hallgren et al.

Table 1. The different sub-datasets used for the complete dataset of ALOMAR data. The spectral resolution given is the effective spectral resolution.

\begin{tabular}{lcccc}
\hline Data version & v3.1 & v3.2 & v3.3 & v3.4 \\
\hline Front-end & WASPAM & WASPAM & WASPAM & cWASPAM \\
Bandwidth [MHz] & 40 & 180 & 40 & 40 \\
No. of channels & 2048 & 4096 & 4096 & 4096 \\
Spectral resolution $[\mathrm{kHz}]$ & 20 & 44 & 10 & 10 \\
In operation & $1995-2004$ & $2002-2005$ & $2004-2006$ & $2008-\ldots$ \\
\hline
\end{tabular}

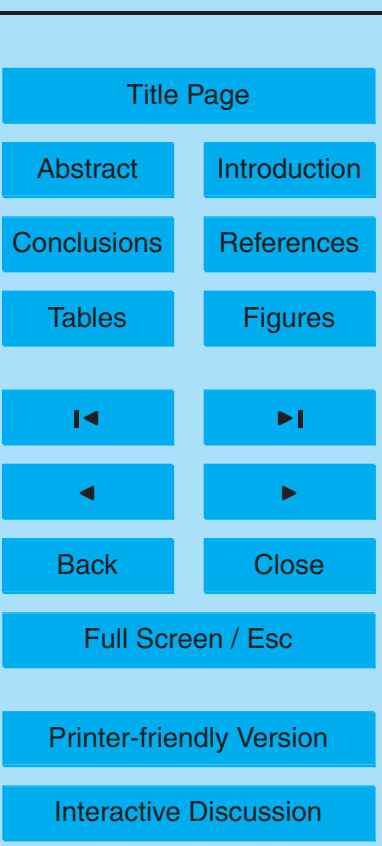


Table 2. A water vapour climatology for ALOMAR, given in week of the year and ppmv.

\section{ACPD}

\begin{tabular}{|c|c|c|c|c|c|c|c|c|c|}
\hline Week/Z[km] & 40.00 & 42.50 & 45.00 & 47.50 & 50.00 & 52.50 & 55.00 & 57.50 & 60.00 \\
\hline 1 & 7.12 & 7.12 & 6.92 & 6.57 & 6.21 & 5.94 & 5.78 & 5.66 & 5.44 \\
\hline 2 & 7.12 & 7.12 & 6.93 & 6.61 & 6.26 & 5.96 & 5.72 & 5.48 & 5.18 \\
\hline 3 & 7.12 & 7.15 & 6.98 & 6.63 & 6.25 & 5.94 & 5.71 & 5.47 & 5.11 \\
\hline 4 & 7.15 & 7.19 & 7.00 & 6.58 & 6.08 & 5.61 & 5.24 & 4.92 & 4.59 \\
\hline 5 & 7.15 & 7.25 & 7.15 & 6.82 & 6.31 & 5.76 & 5.28 & 4.92 & 4.64 \\
\hline 6 & 7.16 & 7.23 & 7.08 & 6.72 & 6.25 & 5.80 & 5.46 & 5.22 & 4.97 \\
\hline 7 & 7.20 & 7.28 & 7.10 & 6.71 & 6.22 & 5.74 & 5.33 & 4.95 & 4.57 \\
\hline 8 & 7.18 & 7.26 & 7.11 & 6.77 & 6.35 & 5.91 & 5.49 & 5.11 & 4.72 \\
\hline 9 & 7.20 & 7.27 & 7.11 & 6.74 & 6.25 & 5.77 & 5.38 & 5.09 & 4.80 \\
\hline 10 & 7.17 & 7.23 & 7.08 & 6.72 & 6.23 & 5.71 & 5.30 & 5.03 & 4.81 \\
\hline 11 & 7.18 & 7.24 & 7.08 & 6.72 & 6.25 & 5.82 & 5.49 & 5.29 & 5.11 \\
\hline 12 & 7.20 & 7.31 & 7.23 & 6.97 & 6.60 & 6.19 & 5.86 & 5.64 & 5.47 \\
\hline 13 & 7.25 & 7.38 & 7.28 & 6.96 & 6.54 & 6.12 & 5.81 & 5.62 & 5.47 \\
\hline 14 & 7.20 & 7.31 & 7.27 & 7.06 & 6.73 & 6.33 & 5.97 & 5.68 & 5.44 \\
\hline 15 & 7.18 & 7.30 & 7.27 & 7.08 & 6.77 & 6.41 & 6.05 & 5.77 & 5.53 \\
\hline 16 & 7.20 & 7.33 & 7.32 & 7.16 & 6.88 & 6.53 & 6.19 & 5.91 & 5.68 \\
\hline 17 & 7.21 & 7.35 & 7.36 & 7.21 & 6.93 & 6.59 & 6.22 & 5.90 & 5.62 \\
\hline 18 & 7.21 & 7.36 & 7.37 & 7.21 & 6.91 & 6.54 & 6.18 & 5.92 & 5.73 \\
\hline 19 & 7.20 & 7.34 & 7.32 & 7.13 & 6.80 & 6.39 & 6.02 & 5.77 & 5.65 \\
\hline 20 & 7.21 & 7.36 & 7.37 & 7.22 & $\begin{array}{l}6.93 \\
6.93\end{array}$ & 6.56 & 6.22 & 5.98 & 5.86 \\
\hline 21 & 7.21 & 7.37 & 7.39 & 7.26 & 6.97 & 6.61 & 6.24 & 5.99 & 5.89 \\
\hline 22 & 7.21 & 7.36 & 7.38 & 7.25 & 6.98 & 6.62 & 6.26 & 6.02 & 5.93 \\
\hline 23 & 7.21 & 7.38 & 7.42 & 7.31 & 7.08 & 6.76 & 6.45 & 6.23 & 6.15 \\
\hline 24 & 7.22 & 7.40 & 7.46 & 7.38 & 7.16 & 6.84 & 6.51 & 6.26 & 6.15 \\
\hline 25 & 7.22 & 7.40 & 7.47 & 7.40 & 7.19 & 6.89 & 6.58 & 6.37 & 6.32 \\
\hline 26 & 7.20 & 7.37 & 7.42 & 7.36 & 7.18 & 6.93 & 6.66 & 6.46 & 6.38 \\
\hline 27 & 7.22 & 7.40 & 7.48 & 7.43 & 7.24 & 6.94 & 6.62 & 6.40 & 6.37 \\
\hline 28 & 7.22 & 7.41 & 7.48 & 7.43 & 7.25 & 7.00 & 6.73 & 6.55 & 6.52 \\
\hline 29 & 7.21 & 7.40 & 7.47 & 7.43 & $\begin{array}{l}7.26 \\
\end{array}$ & 7.02 & 6.78 & 6.63 & 6.60 \\
\hline 30 & $\begin{array}{l}7.22 \\
\end{array}$ & 7.40 & 7.48 & 7.44 & 7.30 & 7.09 & 6.86 & 6.70 & 6.65 \\
\hline 31 & 7.22 & 7.40 & 7.48 & 7.43 & 7.26 & 7.00 & 6.72 & 6.54 & 6.51 \\
\hline 32 & 7.21 & 7.38 & 7.44 & 7.39 & 7.24 & 7.02 & 6.79 & 6.62 & 6.58 \\
\hline 33 & 7.21 & 7.39 & 7.45 & 7.39 & 7.22 & 6.98 & 6.75 & 6.62 & 6.63 \\
\hline 34 & 7.22 & 7.39 & 7.44 & 7.36 & 7.15 & 6.87 & 6.65 & 6.56 & 6.64 \\
\hline 35 & 7.22 & 7.39 & 7.44 & 7.34 & 7.12 & 6.81 & 6.53 & 6.40 & 6.45 \\
\hline 36 & 7.22 & 7.41 & 7.46 & 7.38 & 7.16 & 6.86 & 6.57 & 6.43 & 6.49 \\
\hline 37 & 7.24 & 7.43 & 7.48 & 7.37 & 7.12 & 6.82 & 6.59 & 6.55 & 6.69 \\
\hline 38 & $\begin{array}{l}7.22 \\
\end{array}$ & 7.38 & 7.40 & 7.27 & 7.08 & 6.93 & 6.86 & 6.87 & 6.92 \\
\hline 39 & 7.21 & 7.39 & 7.46 & 7.45 & 7.34 & 7.18 & 7.04 & 6.96 & 6.90 \\
\hline 40 & 7.24 & 7.43 & 7.47 & 7.40 & 7.27 & 7.17 & 7.10 & 7.04 & 6.91 \\
\hline 41 & 7.21 & 7.36 & 7.36 & 7.27 & 7.15 & 7.05 & 6.95 & 6.79 & 6.48 \\
\hline 42 & 7.21 & 7.30 & 7.18 & 6.90 & 6.60 & 6.36 & 6.16 & 5.92 & 5.58 \\
\hline 43 & 7.19 & 7.29 & 7.20 & 6.93 & 6.57 & 6.21 & 5.91 & 5.64 & 5.34 \\
\hline 44 & 7.13 & 7.12 & 6.85 & 6.38 & 5.86 & 5.46 & 5.23 & 5.12 & 4.99 \\
\hline 45 & 7.13 & 7.10 & 6.76 & 6.21 & 5.65 & 5.23 & 5.01 & 4.89 & 4.71 \\
\hline 46 & 7.15 & 7.10 & 6.76 & 6.25 & 5.74 & 5.37 & 5.14 & 4.95 & 4.65 \\
\hline 47 & 7.13 & 7.08 & 6.74 & 6.21 & 5.69 & 5.35 & 5.17 & 5.01 & 4.73 \\
\hline 48 & 7.07 & 6.91 & 6.42 & 5.72 & 5.05 & 4.59 & 4.34 & 4.14 & 3.84 \\
\hline 49 & 7.14 & 7.08 & 6.76 & 6.27 & 5.78 & 5.38 & 5.10 & 4.86 & 4.56 \\
\hline 50 & 7.15 & 7.14 & 6.91 & 6.56 & 6.20 & 5.90 & 5.68 & 5.44 & 5.11 \\
\hline 51 & 7.16 & 7.16 & 6.95 & 6.62 & $\begin{array}{l}6.27 \\
6\end{array}$ & 5.97 & 5.73 & 5.47 & 5.11 \\
\hline 52 & 7.04 & 6.99 & 6.77 & 6.44 & 6.14 & 5.92 & 5.71 & 5.41 & 4.94 \\
\hline
\end{tabular}

12, 31531-31560, 2012

Water vapour above ALOMAR

K. Hallgren et al.

Title Page

\begin{tabular}{|c|c|}
\hline Abstract & Introduction \\
\hline Conclusions & References \\
\hline Tables & Figures \\
\hline I4 \\
\hline 4 \\
\hline Back \\
\hline Full Screen / Esc \\
\hline Printer-friendly Version \\
\hline Interactive Discussion
\end{tabular}


Table 2. Continued from the previous page.

\begin{tabular}{|c|c|c|c|c|c|c|c|c|c|c|}
\hline Week/Z[km] & 62.50 & 65.00 & 67.50 & 70.00 & 72.50 & 75.00 & 77.50 & 80.00 & 82.50 & 85.00 \\
\hline 1 & 5.03 & 4.38 & 3.57 & 2.78 & 2.15 & 1.72 & 1.42 & 1.15 & 0.86 & 0.54 \\
\hline 2 & 4.74 & 4.12 & 3.36 & 2.60 & 1.99 & 1.57 & 1.28 & 1.03 & 0.76 & 0.46 \\
\hline 3 & 4.61 & 3.95 & 3.24 & 2.61 & 2.14 & 1.80 & 1.53 & 1.26 & 0.95 & 0.61 \\
\hline 4 & 4.19 & 3.68 & 3.14 & 2.63 & 2.22 & 1.92 & 1.67 & 1.40 & 1.08 & 0.71 \\
\hline 5 & 4.29 & 3.82 & 3.24 & 2.63 & 2.10 & 1.69 & 1.38 & 1.11 & 0.82 & 0.52 \\
\hline 6 & 4.60 & 4.03 & 3.30 & 2.56 & 1.97 & 1.58 & 1.32 & 1.09 & 0.84 & 0.55 \\
\hline 7 & 4.10 & 3.52 & 2.91 & 2.38 & 1.99 & 1.75 & 1.57 & 1.37 & 1.09 & 0.76 \\
\hline 8 & 4.25 & 3.68 & 3.04 & 2.44 & 1.94 & 1.58 & 1.32 & 1.09 & 0.84 & 0.55 \\
\hline 9 & 4.42 & 3.91 & 3.29 & 2.67 & 2.15 & 1.76 & 1.47 & 1.21 & 0.94 & 0.63 \\
\hline 10 & 4.47 & 3.92 & 3.21 & 2.51 & 1.96 & 1.60 & 1.35 & 1.13 & 0.89 & 0.61 \\
\hline 11 & 4.77 & 4.20 & 3.42 & 2.63 & 2.02 & 1.62 & 1.36 & 1.15 & 0.93 & 0.66 \\
\hline 12 & 5.18 & 4.67 & 3.94 & 3.13 & 2.43 & 1.90 & 1.53 & 1.23 & 0.96 & 0.66 \\
\hline 13 & 5.15 & 4.57 & 3.80 & 3.00 & 2.35 & 1.87 & 1.52 & 1.24 & 0.97 & 0.68 \\
\hline 14 & 5.10 & 4.54 & 3.78 & 2.95 & 2.26 & 1.77 & 1.44 & 1.21 & 0.99 & 0.73 \\
\hline 15 & 5.20 & 4.68 & 3.95 & 3.11 & 2.35 & 1.78 & 1.39 & 1.12 & 0.91 & 0.67 \\
\hline 16 & 5.38 & 4.89 & 4.23 & 3.48 & 2.79 & 2.22 & 1.76 & 1.39 & 1.08 & 0.78 \\
\hline 17 & 5.28 & 4.80 & 4.19 & 3.47 & 2.81 & 2.27 & 1.87 & 1.55 & 1.25 & 0.91 \\
\hline 18 & 5.54 & 5.19 & 4.66 & 3.97 & 3.28 & 2.68 & 2.18 & 1.77 & 1.39 & 0.99 \\
\hline 19 & 5.57 & 5.38 & 5.01 & 4.48 & 3.90 & 3.35 & 2.84 & 2.35 & 1.83 & 1.30 \\
\hline 20 & 5.76 & 5.59 & 5.28 & 4.88 & 4.45 & 3.98 & 3.46 & 2.86 & 2.21 & 1.55 \\
\hline 21 & 5.90 & 5.88 & 5.74 & 5.46 & 5.08 & 4.62 & 4.05 & 3.35 & 2.56 & 1.78 \\
\hline 22 & 5.97 & 6.04 & 6.00 & 5.81 & 5.48 & 4.99 & 4.34 & 3.56 & 2.70 & 1.87 \\
\hline 23 & 6.17 & 6.19 & 6.13 & 5.96 & 5.71 & 5.31 & 4.69 & 3.84 & 2.89 & 1.96 \\
\hline 24 & 6.18 & 6.25 & 6.27 & 6.16 & 5.91 & 5.47 & 4.80 & 3.90 & 2.91 & 1.95 \\
\hline 25 & 6.37 & 6.43 & 6.40 & 6.24 & 5.99 & 5.60 & 5.00 & 4.14 & 3.11 & 2.09 \\
\hline 26 & 6.37 & 6.36 & 6.29 & 6.13 & 5.89 & 5.49 & 4.86 & 3.98 & 2.95 & 1.97 \\
\hline 27 & 6.51 & 6.73 & 6.89 & 6.85 & 6.58 & 6.02 & 5.19 & 4.16 & 3.05 & 2.03 \\
\hline 28 & 6.62 & 6.78 & 6.90 & 6.86 & 6.65 & 6.16 & 5.35 & 4.29 & 3.12 & 2.06 \\
\hline 29 & 6.69 & 6.80 & 6.86 & 6.78 & 6.55 & 6.07 & 5.27 & 4.24 & 3.09 & 2.04 \\
\hline 30 & 6.72 & 6.82 & 6.89 & 6.85 & 6.67 & 6.21 & 5.44 & 4.38 & 3.20 & 2.11 \\
\hline 31 & 6.65 & 6.85 & 6.99 & 6.96 & 6.74 & 6.23 & 5.40 & 4.32 & 3.16 & 2.09 \\
\hline 32 & 6.67 & 6.81 & 6.91 & 6.88 & 6.71 & 6.29 & 5.53 & 4.49 & 3.31 & 2.20 \\
\hline 33 & 6.74 & 6.86 & 6.90 & 6.77 & 6.52 & 6.02 & 5.23 & 4.21 & 3.10 & 2.07 \\
\hline 34 & 6.82 & 6.95 & 6.92 & 6.71 & 6.35 & 5.80 & 5.02 & 4.07 & 3.03 & 2.06 \\
\hline 35 & 6.63 & 6.79 & 6.78 & 6.60 & 6.21 & 5.62 & 4.83 & 3.91 & 2.94 & 2.02 \\
\hline 36 & 6.69 & 6.87 & 6.89 & 6.70 & 6.26 & 5.60 & 4.75 & 3.79 & 2.81 & 1.92 \\
\hline 37 & 6.88 & 6.94 & 6.74 & 6.29 & 5.65 & 4.89 & 4.06 & 3.21 & 2.39 & 1.64 \\
\hline 38 & 6.89 & 6.66 & 6.21 & 5.57 & 4.86 & 4.13 & 3.43 & 2.74 & 2.07 & 1.43 \\
\hline 39 & 6.77 & 6.48 & 5.98 & 5.32 & 4.54 & 3.72 & 2.94 & 2.26 & 1.66 & 1.12 \\
\hline 40 & 6.59 & 6.03 & 5.22 & 4.31 & 3.47 & 2.78 & 2.22 & $\begin{array}{l}1.76 \\
\end{array}$ & 1.34 & 0.92 \\
\hline 41 & 5.97 & 5.32 & 4.55 & 3.77 & 3.08 & 2.51 & 2.05 & 1.64 & 1.25 & 0.86 \\
\hline 42 & 5.06 & 4.40 & 3.62 & 2.88 & 2.28 & 1.85 & 1.53 & 1.26 & 0.97 & 0.67 \\
\hline 43 & 4.90 & 4.35 & 3.72 & 3.11 & 2.60 & 2.18 & 1.84 & 1.51 & 1.17 & 0.80 \\
\hline 44 & 4.73 & 4.27 & 3.66 & 3.04 & 2.52 & 2.12 & 1.79 & 1.49 & 1.15 & 0.79 \\
\hline 45 & 4.39 & 3.87 & 3.27 & 2.69 & 2.23 & 1.89 & 1.63 & 1.36 & 1.06 & 0.73 \\
\hline 46 & 4.22 & 3.64 & 3.05 & 2.54 & 2.15 & 1.86 & 1.61 & 1.34 & 1.04 & 0.69 \\
\hline 47 & 4.28 & 3.67 & 3.03 & 2.46 & 2.04 & 1.75 & $\begin{array}{l}1.52 \\
\end{array}$ & 1.27 & 0.98 & 0.65 \\
\hline 48 & 3.39 & 2.80 & 2.21 & 1.76 & 1.50 & 1.36 & 1.25 & 1.11 & 0.88 & 0.59 \\
\hline 49 & 4.15 & 3.59 & 2.97 & 2.41 & 1.98 & 1.68 & 1.45 & 1.21 & 0.93 & 0.60 \\
\hline 50 & 4.64 & 4.00 & 3.29 & 2.64 & 2.13 & 1.77 & 1.50 & 1.23 & 0.92 & 0.59 \\
\hline 51 & 4.59 & 3.89 & 3.10 & 2.39 & 1.87 & 1.54 & 1.31 & 1.10 & 0.85 & 0.55 \\
\hline 52 & 4.39 & 3.70 & 2.98 & 2.34 & 1.88 & 1.56 & 1.33 & 1.11 & 0.84 & 0.54 \\
\hline
\end{tabular}

Water vapour above ALOMAR

K. Hallgren et al.

Title Page

\begin{tabular}{|c|c|}
\hline Abstract & Introduction \\
\hline Conclusions & References \\
\hline Tables & Figures \\
\hline I4 \\
\hline 4 \\
\hline Back \\
\hline Full Screen / Esc \\
\hline Printer-friendly Version \\
\hline Interactive Discussion
\end{tabular}




\section{ACPD}

12, 31531-31560, 2012

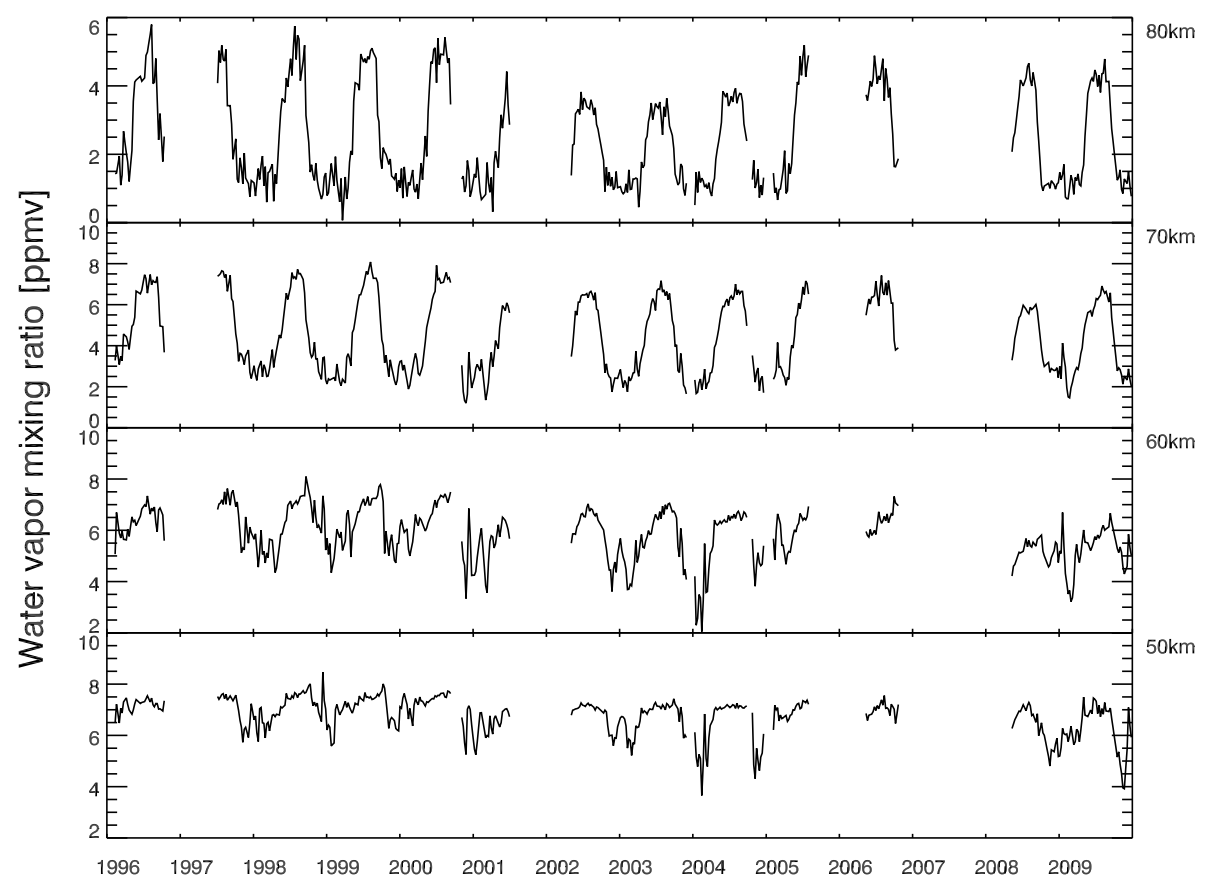

\section{Water vapour above ALOMAR}

K. Hallgren et al.

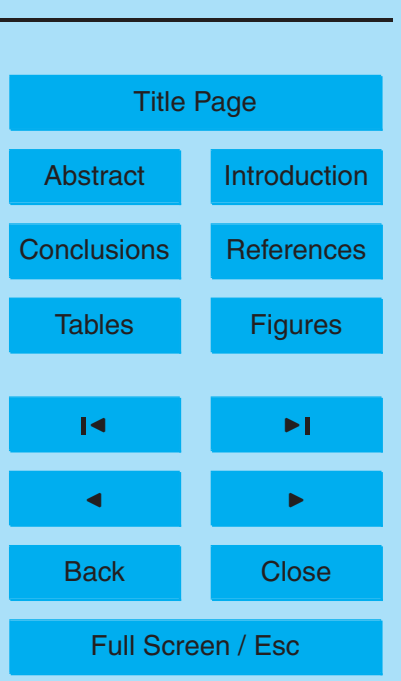

Fig. 1. The full dataset from ALOMAR. Gaps shorter than 3 weeks (3 data-points) have been linearly interpolated and where duplicate data exist data used for the reference profiles have been plotted.

Printer-friendly Version

Interactive Discussion

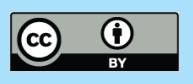




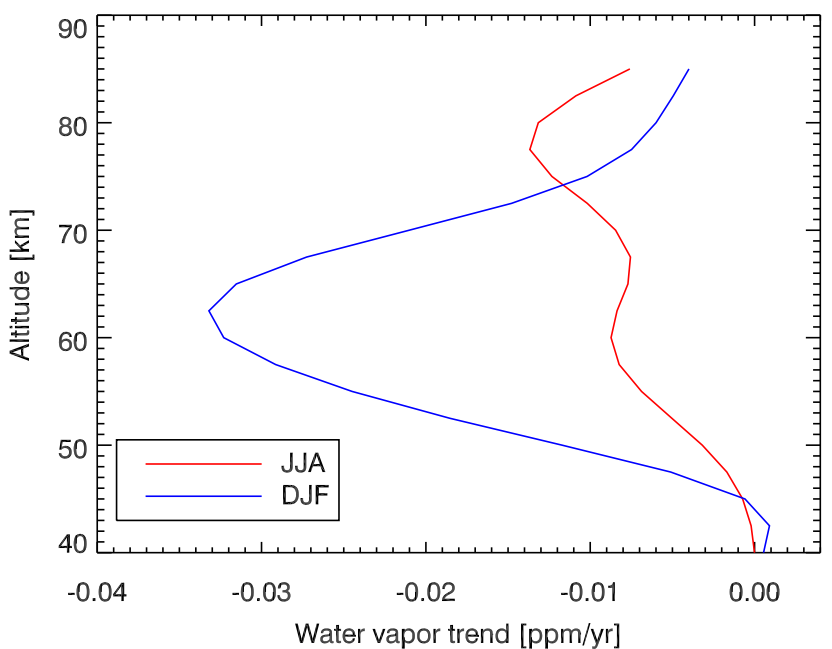

Fig. 2. The trend of water vapour mixing ratios (ppmv) above ALOMAR can be seen here as a function of altitude for summer (JJA, red line) and winter (DJF, blue line) conditions. The strongest decrease is found during winter around $60 \mathrm{~km}$ altitude.

\section{ACPD}

12, 31531-31560, 2012

\section{Water vapour above ALOMAR}

K. Hallgren et al.
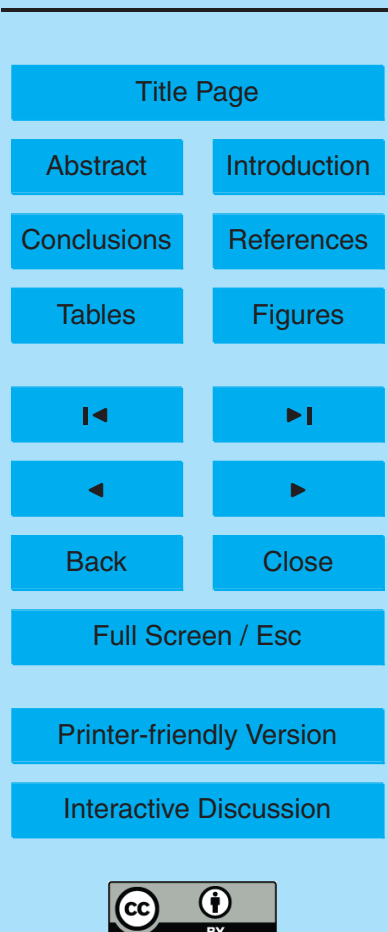


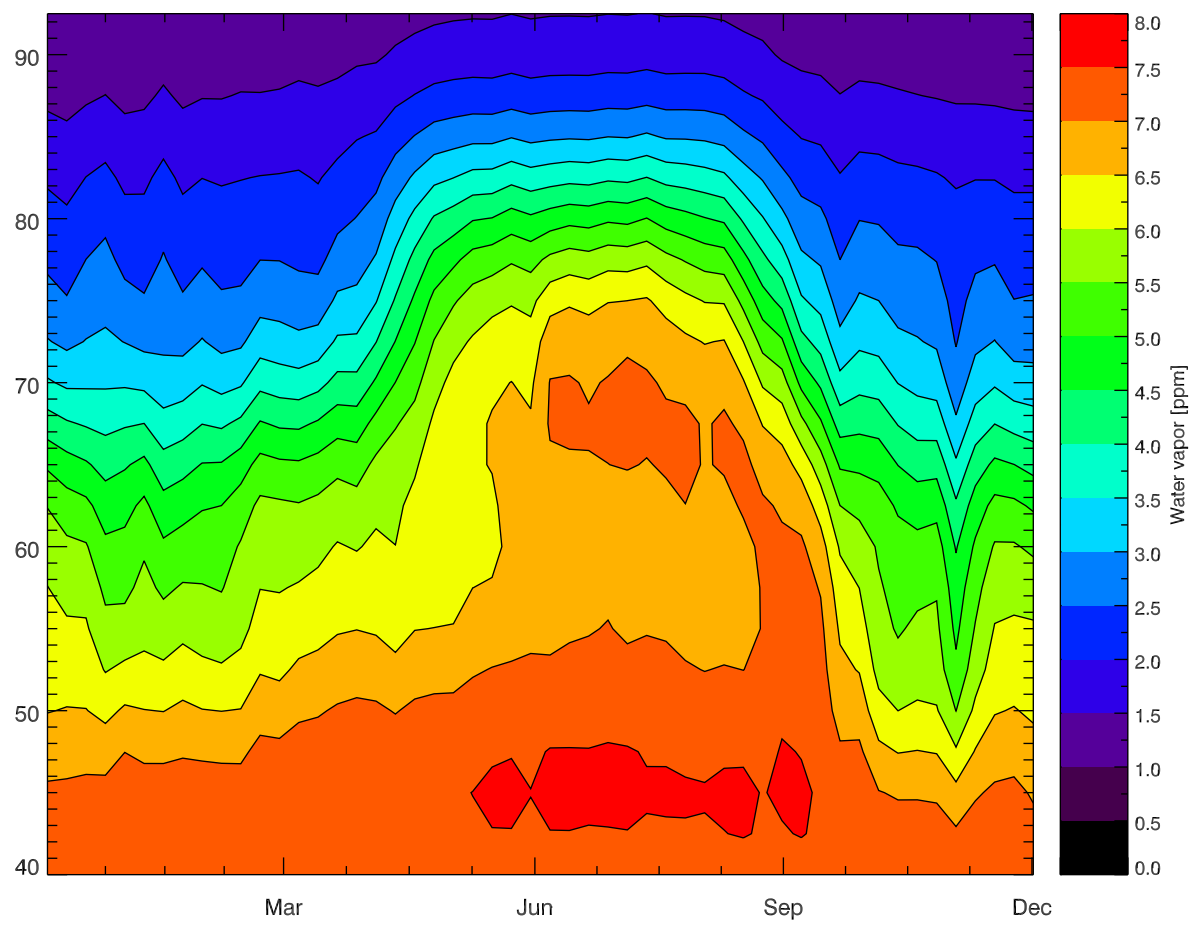

Fig. 3. Weekly mean water vapour values above ALOMAR between 1996 and 2010. The dataset is averaged on a weekly basis and the mean of each bin is plotted as a function of altitude. The values for altitudes above $85 \mathrm{~km}$ are very uncertain due to bad instrumental sensitivity at this altitude.

\section{ACPD}

12, 31531-31560, 2012

\section{Water vapour above ALOMAR}

K. Hallgren et al.

Title Page

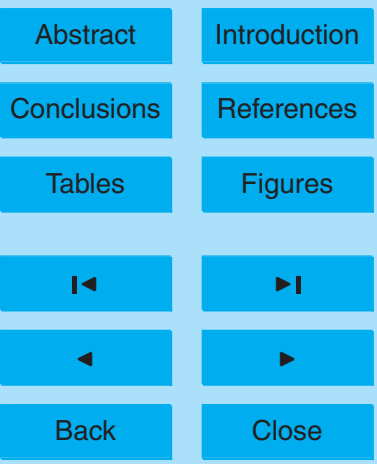

Full Screen / Esc

Printer-friendly Version

Interactive Discussion 


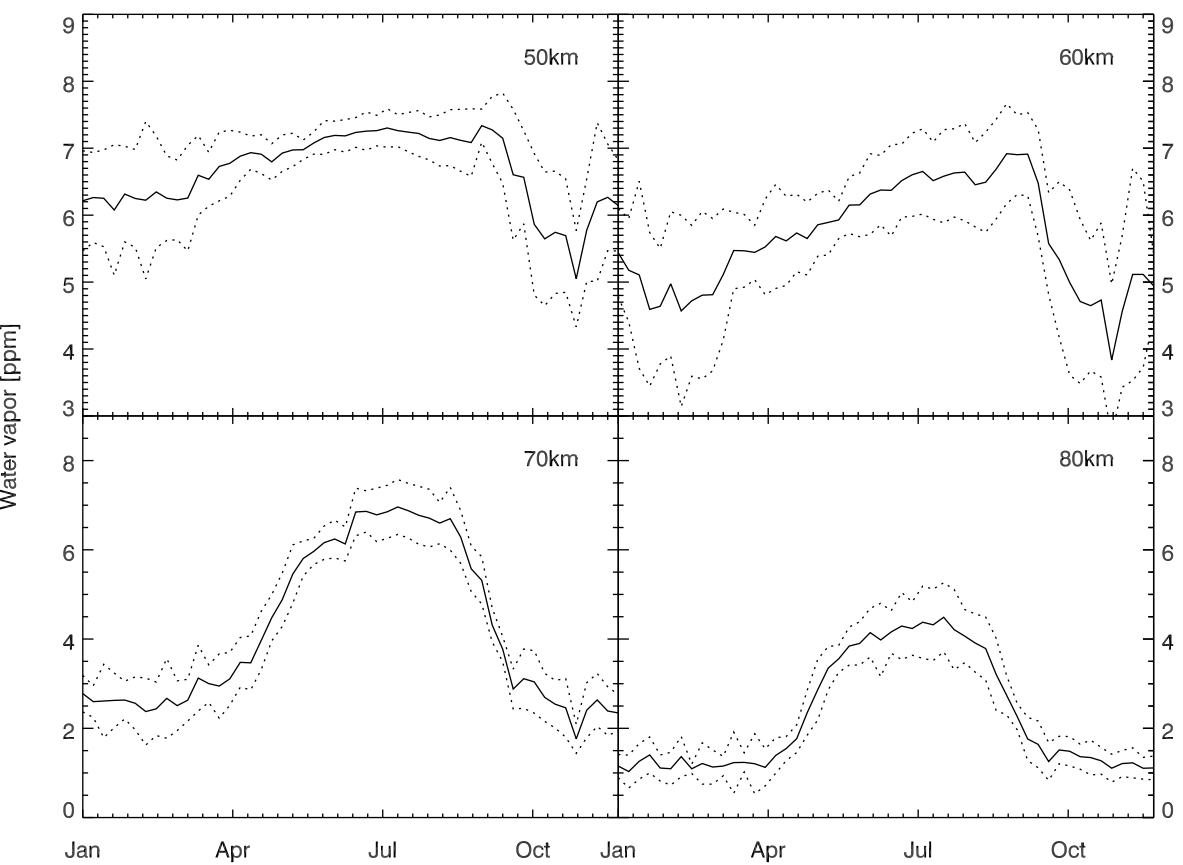

Fig. 4. Same state of affairs as Fig. 3 but only showing four separate layers. The solid line represent the mean whereas the dotted lines represent the variation in each bin.

\section{ACPD}

12, 31531-31560, 2012

\section{Water vapour above ALOMAR}

K. Hallgren et al.

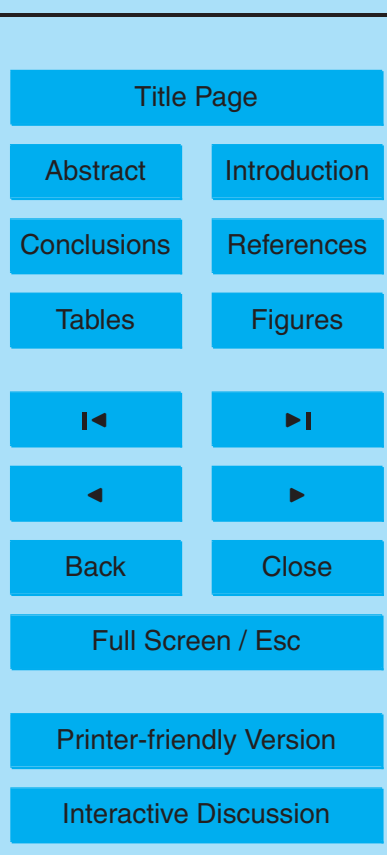

(a) (1) 


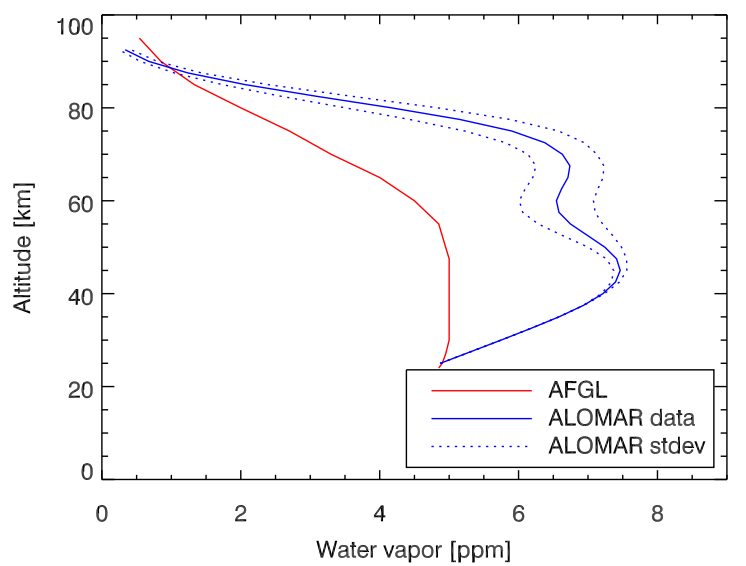

\section{ACPD}

12, 31531-31560, 2012

\section{Water vapour above ALOMAR}

K. Hallgren et al.

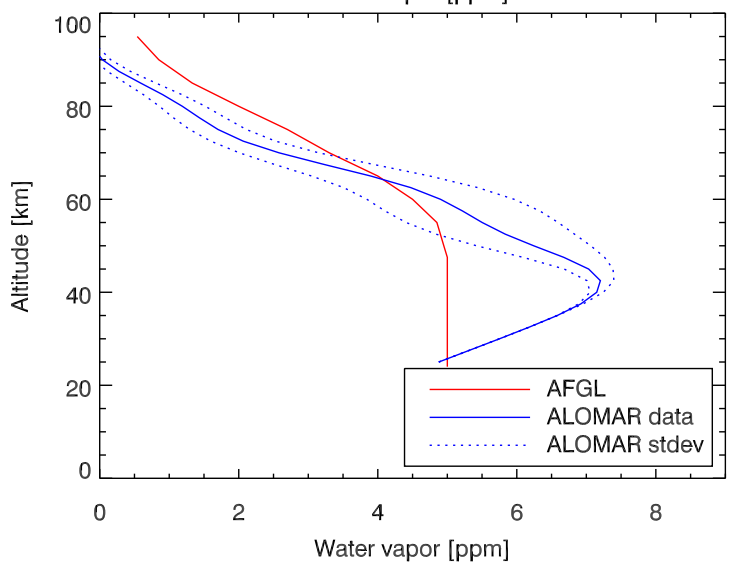

Fig. 5. Comparison of the observed water vapour above ALOMAR to the AFGL Atmospheric constituent profiles for a subarctic location. (a) shows summer (JJA) conditions and (b) winter (DJF) conditions. 